\title{
Ta'tsir Kafaah Mu'allimiy Al Lughah Al 'Arabiyyah fi Natiijah Maharah Al Kitabah Ladaa Thalabah Al Madaaris Al Tsanawiyyah Al Islamiyyah Al Hukumiyyah bi Mujukirtu

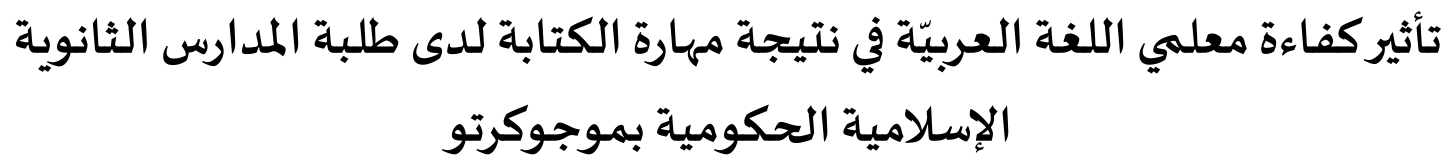

Noviya Ekasanti ${ }^{1}$, E-mail: noviyaekasanti@gmail.com, MAN 1 Mojokerto, Indonesia

Wildana Wargadinata ${ }^{2}$, E-mail : wildana@ bsa.uin-malang.ac.id, UIN Maulana Malik Ibrahim Malang, Indonesia Nur Ila Ifawati ${ }^{3}$, E-mail : nurilahifa2014@gmail.com, UIN Maulana Malik Ibrahim Malang, Indonesia

\section{(c) (1) (2)}

This is an open access article under the CC-BY-SA license

(C)2021 by the authors. Submitted for possible open access publication under the terms and conditions of the Creative Commons Attribution-ShareAlike 4.0 International License-(CC-BY-SA) (https://creativecommons.org/licenses/by-sa/4.0/)

do) DOI: http://dx.doi.org/10.30983/buruf.v1 i2.4939

\begin{abstract}
Teachers are the heart of an education, which through their abilities will be born a young generation who is ready to become a reliable national cadre in all fields. Every teacher is required to have competence in accordance with National Education Standards because teacher competence is considered to have an effect on student learning outcomes. The purpose of this study is to determine the magnitude of: 1.The influence of pedagogical competence 2.The Influence of the Personality Competence. 3.The influence of Social Competence. 4.The influence of Professional Competence of Arabic Language Teachers on the learning outcomes of students' writing skills at MAN Mojokerto. This study uses a quantitative research design. The data analysis model used is Simple Linear Regression with the help of the IBM SPSS 22 application. The results of this study indicate that: 1.The pedagogic competence is in the good category with a significance $=0.001$. The magnitude of the influence of teacher pedagogic competence is 65.4\% affecting the learning outcomes of writing skills, while the rest is influenced by other factors. 2. Personality competence is good with a significance $=0.021$. The magnitude of the teacher's personality competence $43 \%$ affects the learning outcomes of writing skills, while the rest is influenced by other factors. 3. Social competence is good with a significance $=0.004$. The magnitude of the teacher's personality competence $57.9 \%$ affects the learning outcomes of writing skills, while the rest is influenced by other factors. 4. The professional competence is good with a significance = 0.003. The ratio of teachers' professional skills is $60.1 \%$ which affects the learning outcomes of writing skills, while the rest is influenced by other factors. The formal findings of this study are: Teacher competence has an effect on student learning outcomes. Simultaneously, the influence of pedagogic, personality, social, and professional competence is significant on student learning outcomes in writing skills. This means that if teacher competence increases, it will be followed by increased student learning outcomes. Or vice versa if teacher competence decreases, student learning outcomes will also decrease.
\end{abstract}

Keywords: Influence, Teacher Competence, Learning Outcomes on Writing Skill 


\section{ملخص البحث}

إن المعلمين قلب التعليم، وبقدراتهم يمكن أن يطبع جيل الشباب كادر الأمة الموثوقة في جميع

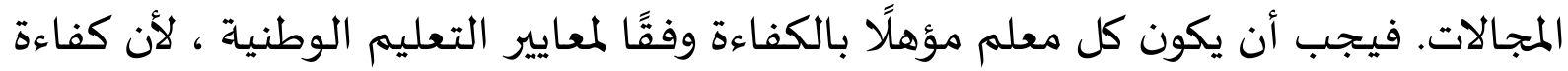
المعلم تعتبر ذات تأثير على نتيجة تعلم الطلبة. والغرض من هذا البحث هو لقياس: 1. 1. تأثير

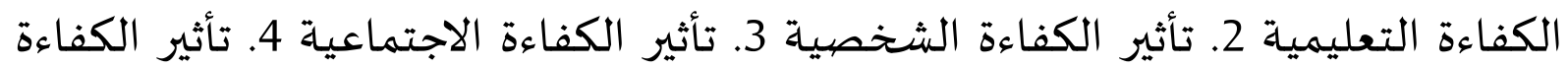
المهنية لمعلمي اللغة العربية في نتيجة تعلم مهارة الكتابة لدى الطلبة في المدارس الثانوية الإسلامية بموجوكرتو. تستخدم هذه الدراسة تصهيم بحث كمي. وأسلوب تحليل البيانات

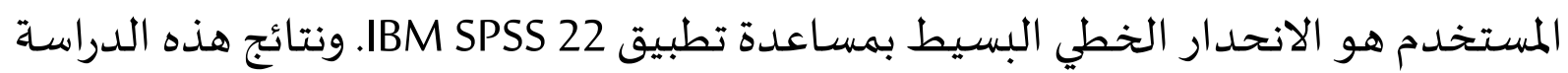

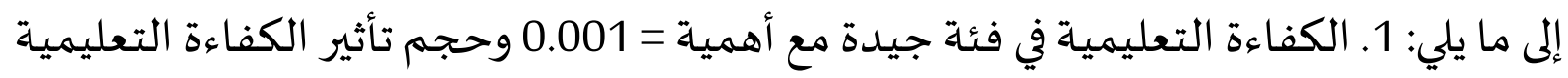
للمعلمين 65.4٪ تؤثر على نتيجة تعلم مهارة الكتابة بينما تتأثر الباقية بعوامل أخرى 2.

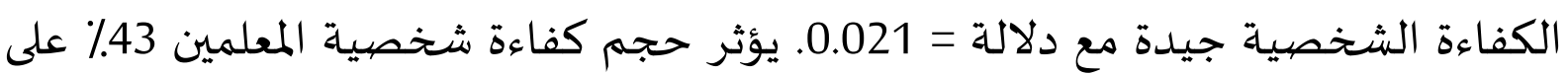

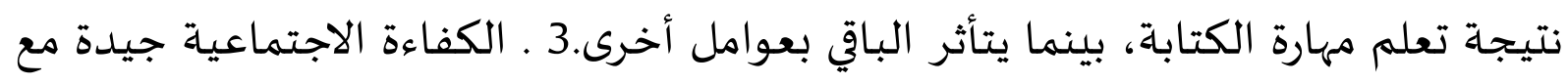

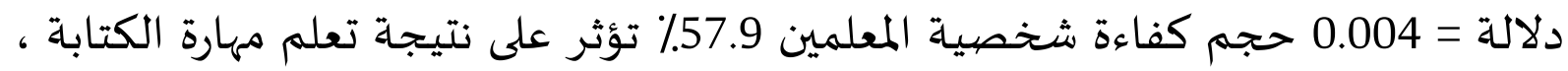
بينما يتأثر الباقي بعوامل أخرى 4. الكفاءة المهنية جيد مع دلالة = 0.003. نسبة المهارة المهنية

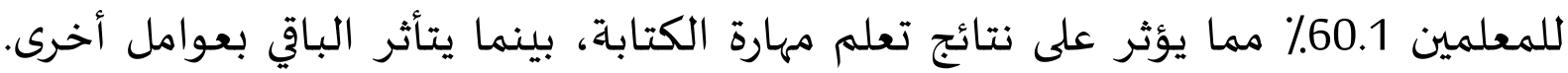

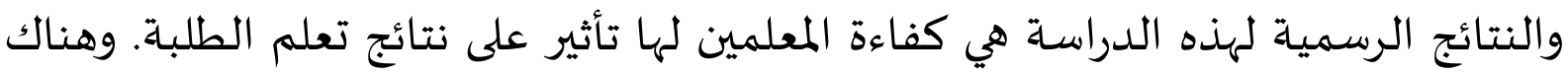

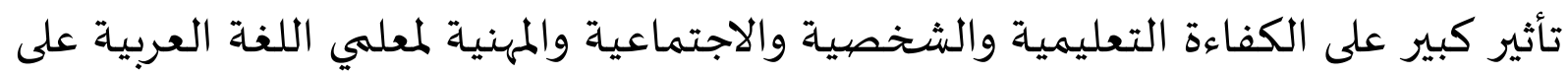

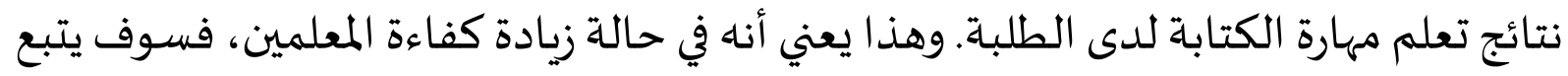

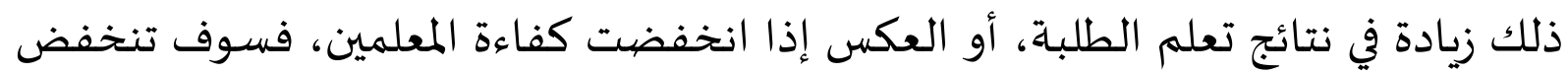
أيضًا نتائج تعلم الطلبة. الكلمات المحورية: تأثير كفاءة معلميي اللغة العـبيّة أنتيجة بمهارة الكتابة مقدمة - مقاك

هدف التعلم نقل المعرفة إلى الأخر من العلوم والمعلومات، يجب أن يواجه الناس

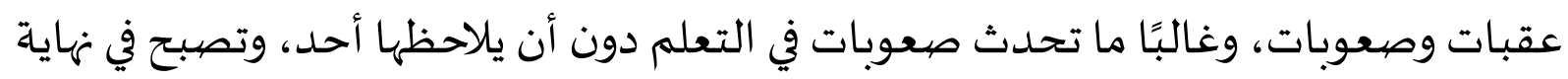

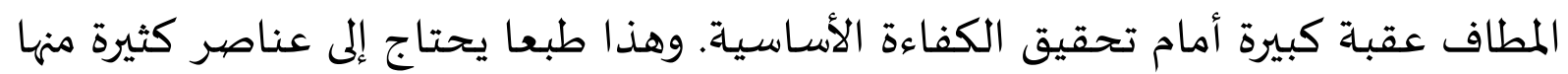


المعلم والطالب والمادة الدراسية والمنهج الدراسي والمرافق والإدارة والبيئة. وللمعلم كفاءة

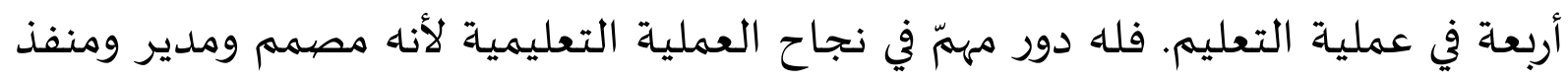

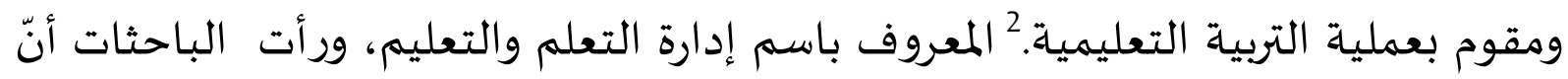
المعلم وكفاءته أمر ضروري لنجاح البرامج التعليمياة. أمّا الأسباب العديدة كخلفية البحث هي يعتقد الطلبة أن اللغة العربية ليست مهمة

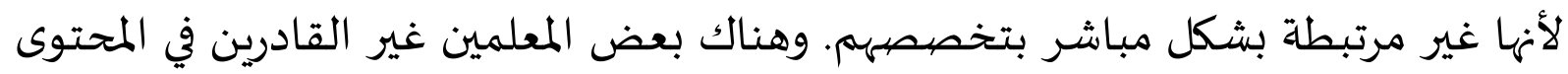

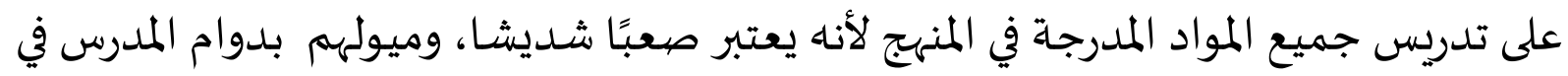
فصول معينة دون تغييرات في المواد التعليمية، مما يتسبب في أن لا يكون المعلم تطوراً كثيرا. لم يكن المعلمون تطوير الوسائط التعليمية بحيث تجعل التعلم مملاً وأقل إثارة للإهتمام.

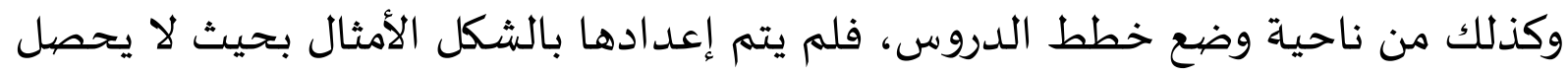

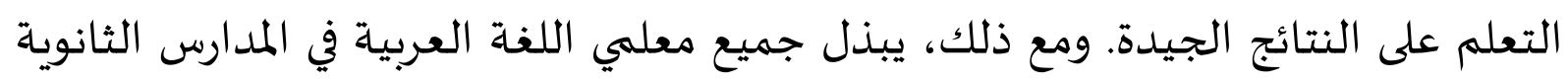
الإسلامية الحكومية بموجوكرتو قصارى جهدهم لتقديم أفضل تعليم كمبدأ أساسي في

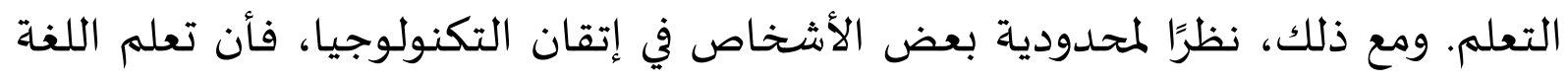
العربية أمر رتيب بعض الشيء.

والأسباب الأخرى هي شعور الطلبة في تعليم اللغة العربية لأنهم يواجهون صعوبة في ماتئي إتقاها واكتسابها واعتقادا بأهها مادة صعبة لكثير من الطلبة. ولم يكن الطلبة في المدرسة

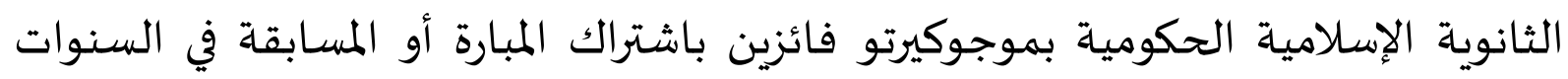

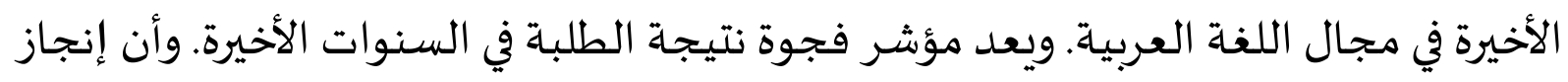

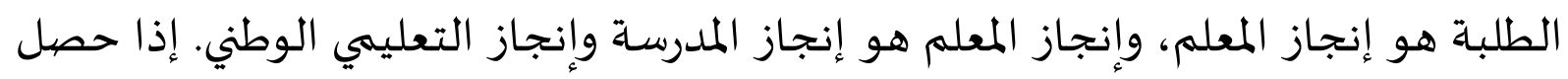
الطلبة على بطل أو جائزة، فهذا دليل على جودة كفاءة المعلم المتتطور بشكل متزايد.

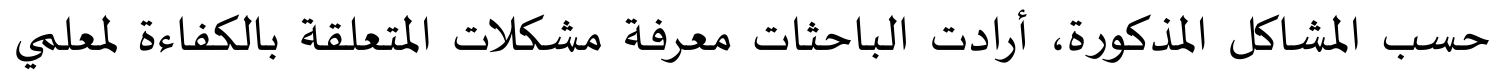

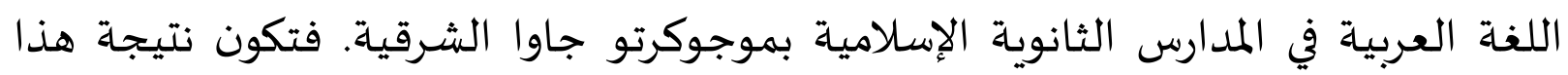
البحث نظرية وتطبيقية لترقية جودة تعليم المعلمين في المدارس الثانوية الإسلامية الحكومية Aksara, n.d.).

${ }^{1}$ Suharsimi Arikunto and Cepi Safrudin Abdul Jabar, Evaluasi ProgramPpendidikan (Jakarta: Bumi

${ }^{2}$ Syafrudin Nurdin and Basyirudin Usman, Guru Profesional Dan Implementasi Kurikulum (Jakarta: Ciputat Pers, n.d.). 
بموجوكرتو. فأقامت بحثا تحت العنوان تأثير كفاءة معلمي اللغة العربيّة في نتيجة مهارة الكتابة للطلبـة المدارس الثانويـة الإسلامية بموجوكرتو. أن حدود هي تأثير كفاءات المعلم الأربعة في درس اللغة العربية في نتيدجة مهارة الكتابة لدي طلبة المدارس الثانوية الإسالامية الحكومياة. والكفاءات هي الكفاءة التعليمية والكفاءة الشخصية والكفاءة الاجتماعية والكفاءة المهنية. ومن ناحية مهارة الكتاباة، حددت الباحثات تعلم الكتابة للمستوي المتقدمين هي ترتيب الجمل والإنشاء المواجهة والإنشاء التحرير مثل الكتابة الوصفية. الفصل الدراسي الثاني من 9 مارس حتى 24 إبريل اب .rالعام الدراسي . T. YI/ T. T.

مناسبا لهذا الموضوع التي استفادت الباحثات هي الدراسـات السابقة المتعلقة بالكفاءات هي دراسة وحيو هوتاما سوريا، ( 19 . (Y) عنوان البحث هي تأثير الكفاءة المهنية لمدرس اللغة العربية على نتيدجة تعلم طلاب نهضية العلماء الأولى المتوسطة ببورووجاتى فى السنة الدراسية 2019-2020. هذا البحث ميدانيا، والأسـاليب هي المراقبة والتوثيق والمقابلة. بينما يستخدم التحليل الاختبار chi square نتيجة الاختبار الفرضية باستخدام الاختبار بيانات قيمة حصلت نتيجة 0 chi square الإيجابي (Ha) الذي يقال "يوجد تأثير الكفاءة المهنية لمدرس اللغة العربية على نتيجة التعلم الطلبة بمدرسـة معارف نهضية العلماء الأولى المتوسطة ببورووجاتى فى السنة الدراسية 2019-

والدراسـة الثانية هي دراسـة أحمد علي مغفور، (. . . (Y) عنوان هذا البحث هي تأثير كفاءة معلمي اللغة العربية التعليمياة والمهنيّة في ترقياة إنجاز الطلبـة. استخدمت هذه الرسالة بمدخل الكمى بالدراسـة الإرتباطية. وأما نتائج البحث هي التأثير الكبير للكفاءة التعليمية لمعلمي اللغة العربية على إنجاز الطلبة في المدرسـة الثانوية الحكومية 1 ببجانغارا وله تأثير في ترقيـة إنجاز الطلبـة.

3 وحيو هوتاما, "لثأثير الكفاءة المهنية لمسربس اللغة العربية على نتيجة تعلم طلاب نهضية العلماء الأولى المتوسطة

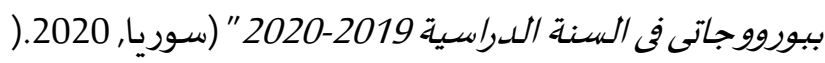
4 أحمد علي. مغفور تأثيركفاءة معلمي اللغة العبنية التعليمية والمهنيّة في ترقية إنجاز الطلبة) مالانج: الجامعاة

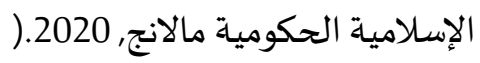


والدراسة الثالثة هي دراسة محمد إحسان، ( 2018) عنوان البحث هي كفاءات

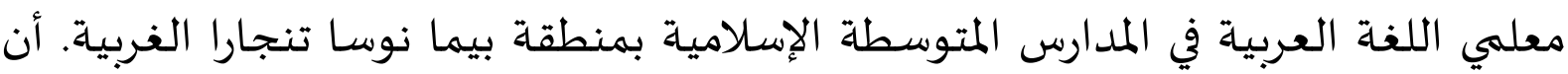

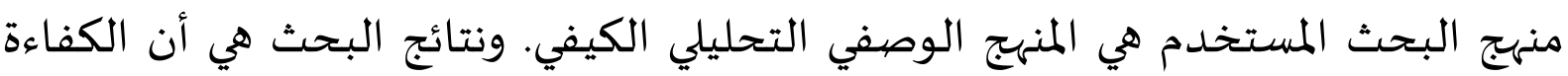
التعليمية للمعلم اللغة العربية في المدارس المتوسطة الإسلامية بمنطقة بيما نوسا تنجارا الغربية بالمعايير على الكفاءات ولكن بعضهم لم يملك على خطه التدريس. أما الكفاءة المهنية

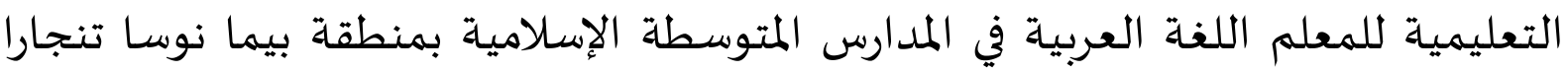

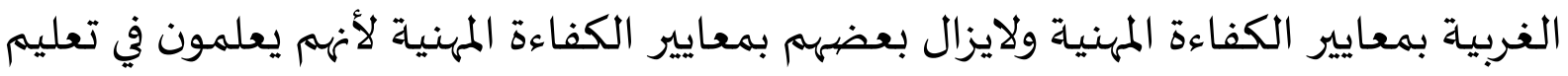
اللغة العربية غير مناسبة بقسمههم في الدراسة. 5 انطلاقا من البحوث السابقة أراد الباحثون بحث تأثير كفاءة معلمي اللغة العبربية في المدارس الثانوية الإسلامية الحكومية بموجوكرتو. وكانت الإختلاف من جانب الموضوع عن لمانيان

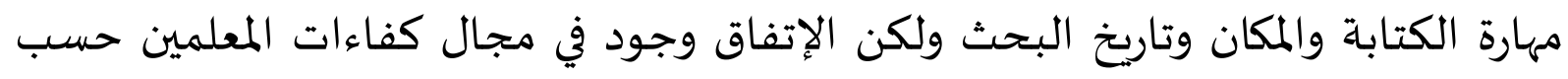

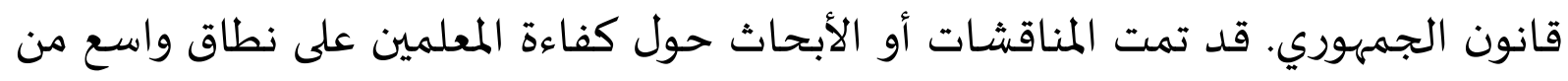
قبل الباحثين، ولكن البحث عن هذه الكفاءات لا تزال مثيرة للمناقشة لأن لكل المنطقة

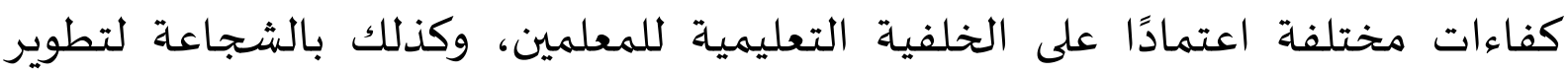
الأساليب والوسائط في التعليم في نتيجة مهارة الكتابة.

\section{الإطار النظري \\ كفاءات المعله}

الكفاءة هي السلطة أو السلطة لتحديد أو صياغة شيء, فهم الكفاءات الأسـاسية هي

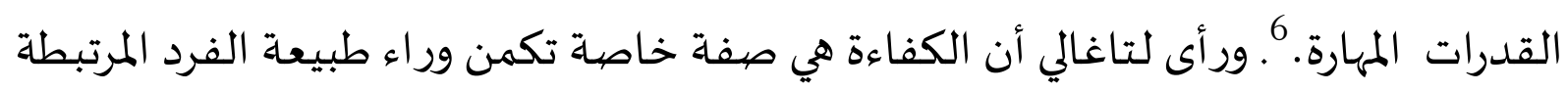

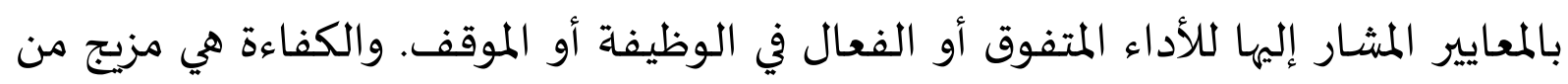

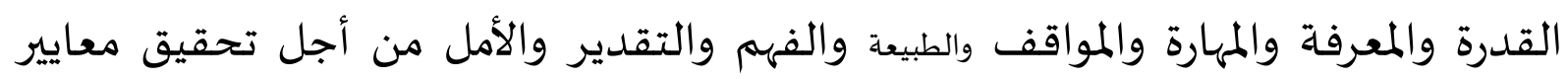

5 محمد. إحسان ,كفاءات معلمي اللغة العربية في المدارس المتوسطة الإسلامية بمنطقة بيما نوسا تنجارا الغربية) مالانج: الجامعة الإسلامية الحكومية 719-20.

${ }^{6}$ Tim Penyusun Kamus Pusat Bahasa, Kamus Besar Bahasa Indonesia (Jakarta: Balai Pustaka, 2008), 
الجودة في وظيفتـه حقيقية وهكذا فإن الكفاءة هي مجموعة من المعارف والمهارة والسلوكيات للمعلمين

والمعلم هو اسم فاعل للفعل علّم، أي قام بفعل التعليم، والمعلم هو الذي يقوم بتربية وتعليم المتعلمين وذلك بتوجياء وبإعطاء جميع الخبرات التي يكتسبها للمتعلم بطرق ووسائل بسيطة والفهم حتى تجعل المتعلم يتقبله بسهولة، إذن فهو اللبنة الأسـاسية لعملية التعليم المعلم وهو القائد للمجتمع ويقوم نشأة الأجيال للمستقبل. قال الإمام الغزالي أن التربية والتعليم أفضل وأشرف وأنبل مهنة بعد النبوة. 8 المعلم أو المدرس هو من الذي يوفر التعليم للتلاميذ (الأطفال) والطلبة (للبالغين). ودور المعلم الرسهي في كثير من الأحيان، والمستمرة في المدرسة كانت أم أي مكان آخر. وفي كثير من البلدان، لابد للشخص راغب أن يكون مدرسا، فعليه حصول على مؤهلات مهنية محددة أو أوراق الإعتماد من جامعة أو كلية. وعند مولياسا أن المعلم مكون مههم في جودة التربية التامة.9 وفي بعض البلدان، تتم التعليم النظامي من خلال التعليم المنتلي. التعلم غير الرسمي يجوز أن يساعده المعلم تحتل دورا عابرة أومستمرة، مثل أحد أفراد الأسرة، والمعلمون في الدينية والروحية، مثل مثل مثرية الحاخامات والقساوسة الشباب أو اللامات بتقديم تعليم النصوص الدينية مثل القرآن والتوراة أو الكتاب المقدس. المصطلحان يعنيان بشكل مختلف قليلاً. غالبًا ما يستخدم مصطلح المدرس في بيئة رسمية، بينما يتم استخدام المعلم في البيئات الرسمية وغير الرسمية. وبالتالي يمكن تسمية المعلم بالمدرس ويمكن تسمية المدرس بالمعلم.10وفي قانون المعلمين والمحاضرين قانون رقم 14 لسنة 2005 أن المعلم المسمّي بالملنيّ إذا كان له أربع كفاءات أساسية، وهي الكفاءات الشخصيية والتعليمية والمهنية والاجتماعية. وفقًا للباحثات، فإن المعلم هو الشخص من يتخل عن كل معارفه وقدراته وأفكاره وروحه وجسده على تعليم وتوجياه وتقديم تغيرات في جميع الأنحاء، بيئة تعليمية كانت أم اجتماعية أوسع. وظيفتهم لجعل طلابه ناجحين مصلحين بالمعارف والأخلاق الحسنة.

${ }^{7}$ Syaiful Sagala, kemampuan profesional guru dan tenaga kependidikan (Bandung: Alfabeta, 2019), 29. 8 الدكتور زكريا. خنجي, “المعلم أدواره وأهميته in ",أخبار الخليج الجريدة اليومية الأولى. 2021, قضايا ,واراء ,

${ }^{9}$ E Mulyasa, Standar Kompetensi Dan Sertifikasi Guru (Bandung: PT Remaja Rosdakarya, n.d.). n.d.

${ }^{10}$ Hajar Istia Rahmi Az Zahra, "Konsep Guru Menurut Ahmad Tafsir: Kontribusinya Terhadap Pendidikan Di Indonesia,” Repository.UMY, 2018. 
كفاءة المعلم

للتعليم عبارة كمبنى تدعماه أعمدة صلبة، ويكون المعلم تركيز التعليم أن يكافئ نجاح التعليم تلقائيًا بكفاءة المعلم النابغة. هي كفاءات المعلم وفقا للقانون رقم 14 لسنة 2005 تصف المادة 10 منها الكفاءة التربوية أو التعليمية والكفاءة الاجتماعية وكفاءة الشخصية والكفاءة المهنية. إن كان أحدها مفقودًا، فستكون حياة المعلم عشوائية وغير متوازنة. لذلك،

يجب علي المعلم أن يتمتع بهذه الكفاءات الأربعة لتحقيق الأهداف وفقًا للمعايير الوطنية.

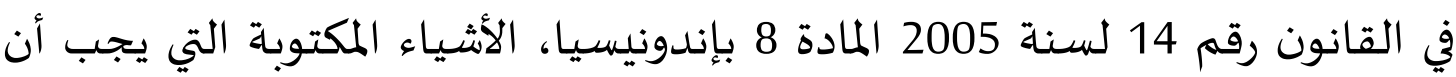

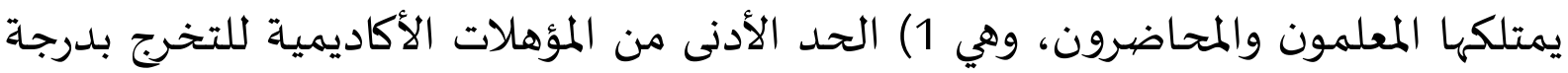

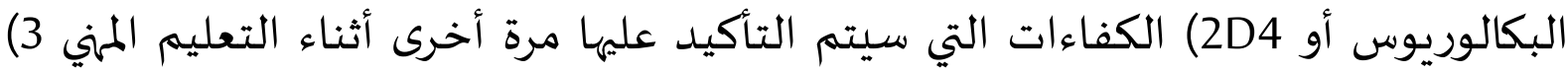

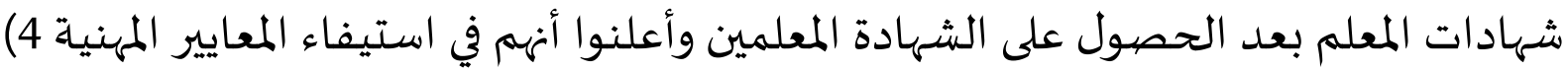
الصحة البدنية والعقلية 5) القدرة على دعم تحقيق أهداف التعليم الوطني.12

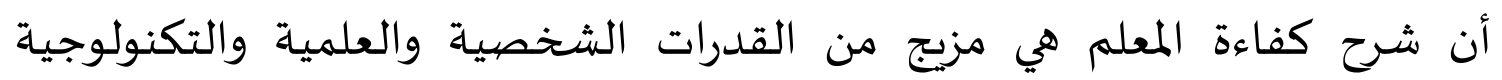

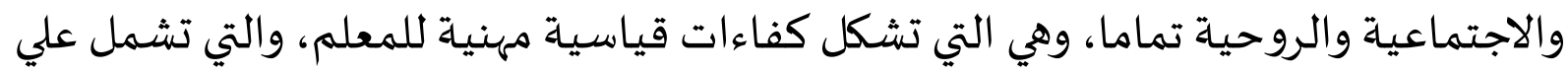
إتقان المواد وفهم الطلبة والتعلم التربوي والتنمية الشخصية والمهنية. وكفاءة المعلم هي مقياس محددة أو مطلوبة في إتقان المعرفة والسلوك للمعلم ليكون مؤهلاً لوظيفته وفقًا لمجال الواجب والمؤهلات والمستوى التعليمي. وتبرز الكفاءة العلمياة الكفاءة الأخلاقية لأن

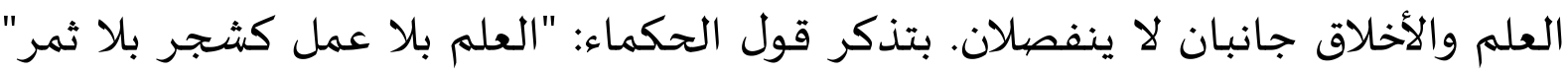
و"العلم بلا عمل كنحل بلا عسل". مثل فعل شييٍ لا فائدة له. الكفاءات الأسـاسية للمعلم أن الكفاءات الأساسية للمعلم تشمل على أربع كفاءات. وهذه الكفاءات مطابقا في القانون رقم 14 لسنة 2005 المادة 10 بإندونيسيا. 1) الكفاءة التعلمية أو التربوياة، أي إتقان وفهم الشخصية وتحديد إنكانديانيات إنسات التعلم

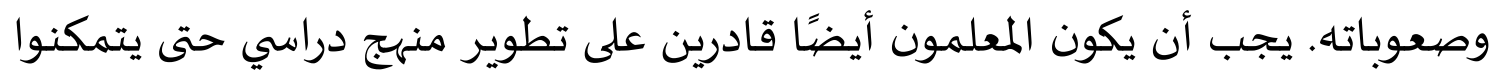

11 D.E.P.D.I.K.N.A.S., UU RI Nomor 14 Tahun 2005 Tentang Guru Dan Dosen (Jakarta: DEPDIKNAS, n.d.).

12 DEPDIKNAS, “UU RI Nomor 14 Tahun 2005 Tentang Guru Dan Dosen.” 
من عمل تصميمات تعليمية ممتعة والإستفادة من التكنولوجيا والمعلومات للأغراض

$$
\text { التعليمياة. }
$$

2) كفاءة الشخصية، أي القدرة على أن تكون نموذجًا يحتذى باه في المواقف الإيجابية.

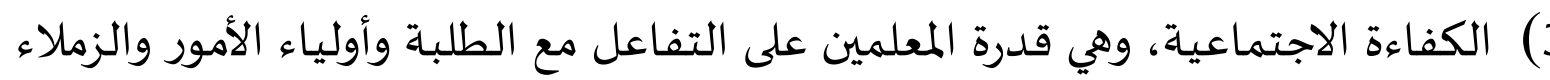

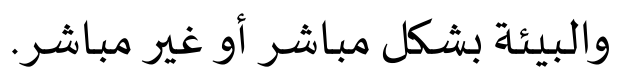
4) الكفاءة المهنية، وهي مهارة المعلم في تنفيذ الأمور المتعلقة بالإحتراف والتي تظهر في قدرتاته على تطوير المسؤولية والقيام بالأدوار بشكل جيد والسعي لتحقيق الأهداف التربوية

$$
\text { والقيام بدوره في التعلم الصفي. } 13
$$

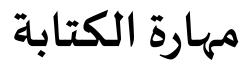

أن مفهوم مهارة الكتابة هي مزيج من عناصر منفصلة لتشكل مجتمعةً كلا واحدا وطريقة لجمع هذه العناصر أو ربطها. وأمثلة التأليف في مهارة اللغة هي مهنارئ مهارة مهارة أو عمل تأليف عمل أدبي (مثل الروايات والخطب والقصائد) ومقالة قصيرة، خاصية واحدة مكتوبة كتمرين أكاديمي المقال عبارة عن تركيبة أدبية قصيرة حول موضيوع معين. وهناك العديد العيد من أنواع

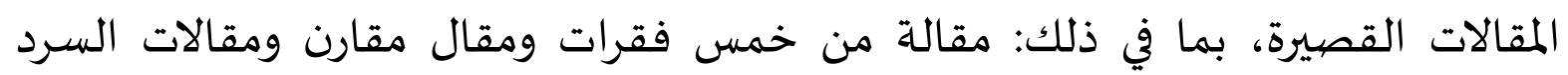

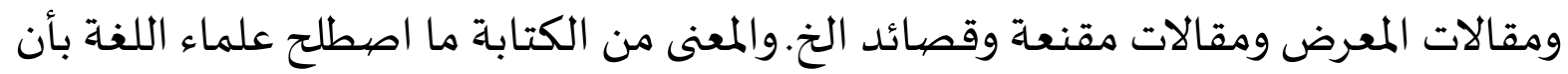

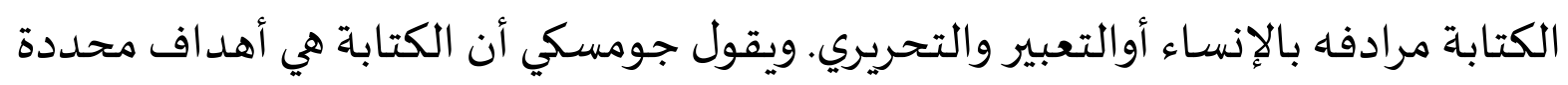

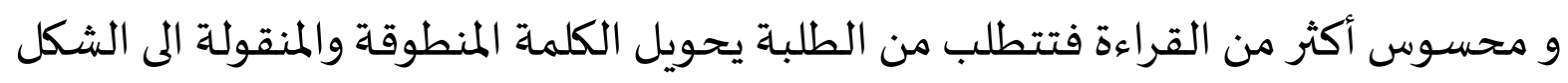
المكتوب.

وفي القاموس الإندونيسي الكبير (KBBI) أن الكتابة هي طريقة للكتابة أو تكوين الحروف وأرقام وما إلى ذلك بقلم ليتعلم الشخص تعبيرالأفكار أو المشاعر مثل الإنشاء

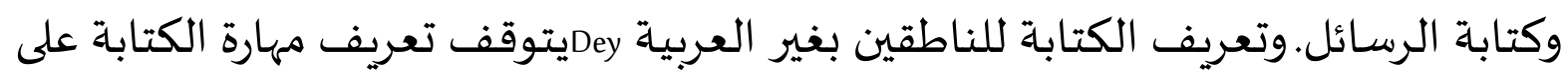

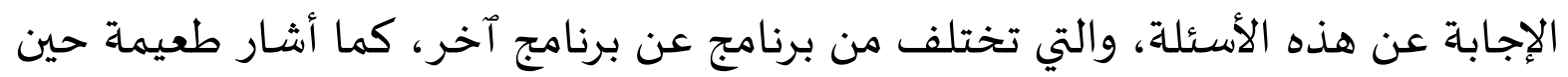

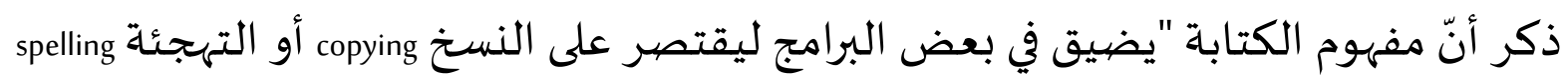

${ }^{13}$ Wahidmurni, Keterampilan Dasar Mengajar (Yogjakarta: Ar-Ruzz Media, n.d.).

14 فتح. الموجود ,مدخل الى تدريس اللغة العربية) متارام: مؤسسـاء الم تر.(n.d.) 
ويتسع في بعضها الآخر حتى يشمل مختلف العمليات العقلية اللازمة للتعبير عن النفس". 15

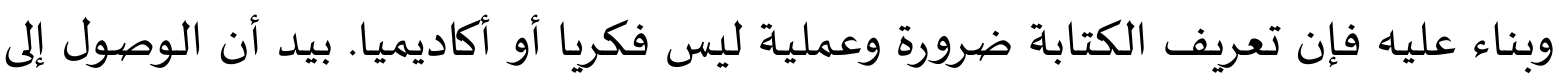

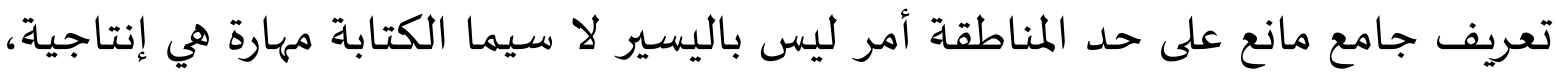
تتطلب من المتعلم التمكن من اللغة فهما وإنتاجا، وهذا ما دفع أحد الباحثين إلى القول

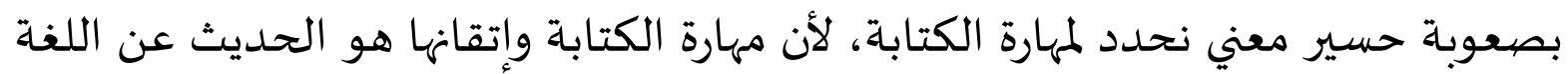
برمتها").

الكتابة وسيلة من وسائل الاتصال اللغوي بين الأشخاص. وهي في سبيل مثل

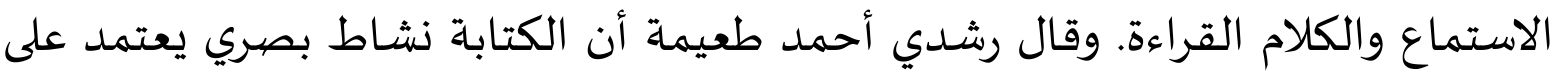

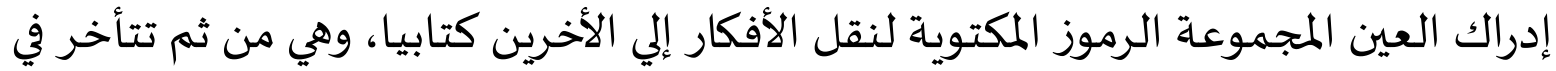

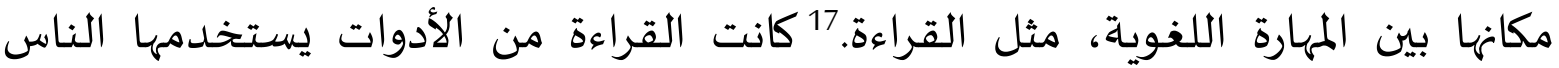

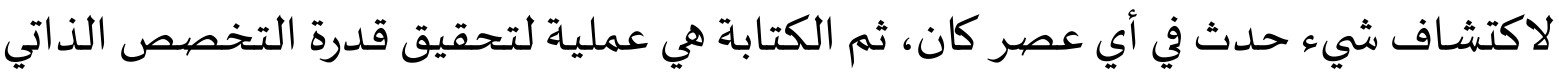

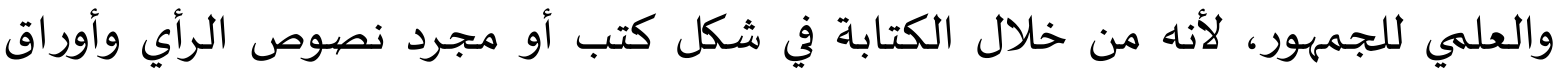

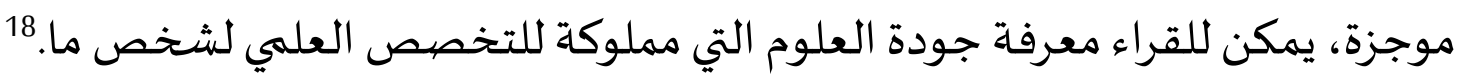
عند ميك روبرتس في الوسيلة، أن مقارنة الألفاظ والكتابة مثل لعباة شطرنج ولعبة العبة الثعابين والسلالم. لديهما هدف واحد نفساه ولكن كيفية السيطرة وعملية التفكير بأنماط مختلفة. 19 الكتابة لا يقتصر على الزمان والمكان، وخلال الكتابة يمكن للجمههور الوصول إلى لئه ملايين الأشخاص. المشكلات وأكبر عقبة هي أههم ما زالوا لا يستطيعون كتابة الأشياء بشكل جيد حتي يشعر المعلم بالتردد في عملية التدريس بسبب صعوبة عالية لنيل الغاية ويتطلب ممارسة

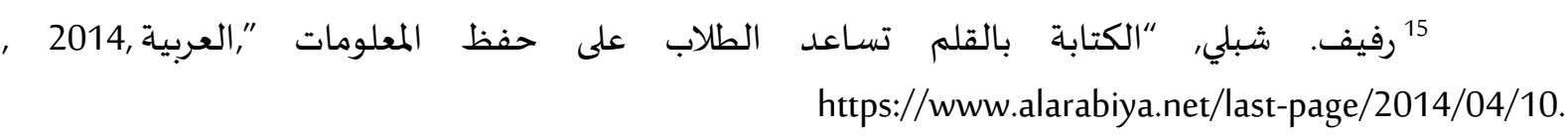
16 رشدي أحمد طعيمة, تعليم العببية لغير الناطقين بها مناهجه وأساليبه (الرباط, مغرب: منشورات المنظمة الإسلامية للتربية والعلوم والثقافة, 1989), 187. 17

${ }^{18}$ Sitti Kuraedah, "Aplikasi Maharah Kitabah Dalam Pembelajaran Bahasa Arab,” Al-TA'DIB: Jurnal Kajian Ilmu Kependidikan 8, no. 2 (2015): 83.

43.

${ }^{19}$ A Chaedar Al Wasilah and Senny Susana, Pokoknya Menulis (Bandung: Kiblat Buku Utama, 2008),

${ }^{20}$ Kuraedah, "Aplikasi Maharah Kitabah Dalam Pembelajaran Bahasa Arab,” 83. 
مستمرّة عليها. وقد يفكّر بعض الناس أن الكتابة أمر سهل لأنهم يفترضون اللغة المكتوبة مطابقة للغـة الشفويـة. مع أن الكتابة أمر لا تصب الكلمات فحسب أو مجرد كلام نفسـه. أي أن الكتابة ليس مثل الكلام قط، بل الكتابة ينطوي على عمل وإجتهاد كبير لتحقيق الكتابة الغالية. أهها مضيعة للغاية عندما أطلب المعلّم الطلبة أن يكتبوا ولكن لا تفحصها ولا تصحّحها أبدًا وأعده. فكيف أحوال الطلبة ليعرفوا كون كتابتهم إذا كانت الكتابة صحيحة أم خاطئة لا يوجد تصحيحا من المعلم. ويجب أن يكون لديه المعلومات الأوسع حول الأسـاليب التي يجب أن تكون مستعدة لإجراء عملية التدريس والتعليم. إذا لم يكن لدى المعلم طريقة فسوف يميل التعلم إلى الفشل. يجب على المعلم معرفة كيفية وتطبيقاه في التعلم من أجل تحقيق أهداف التعلم. فإن الطريقة تلعب دورًا مهمًا في نقل المعرفة للحصول على أقصى النتائج. أن أهمية مهارة الكتابة من وسائل التواصل اللغوي المنطوق للغة كتابيا، فإن الكتابة هي جميع المعلومات تعرف بالدلالة عليها من خلال الإشـارة، أو الخط أو مؤلفة. والإشارة تتوقف على المشاهِدة، ويتوقف اللفظ على حضيور المخاطب،لأن خطب مكتوب منفصل عن مؤلفها. 21

والهدف الرئيسي من تعليم مهارة الكتابة هي الوصول بالمتعلم إلى إتقان الكتابة باللغة العربية إملاء وتعبيرا، بحيث يستطيع المتعلم أن ينسخ أو يملئ أي نص عربي،كما يستطيع أيضا أن يعبر أي فكرة تجول بخاذر بلغة واضحة وصحيحة، و"يمكن تلخيص أهداف تعليه الكتابة في هدف رئيسي هو السيطرة على استخلدام نظام بناء الجملة العربية في كتابة رسالة أو موضيوع يستطيع العربي أن يفهه" . أن مرحلة تعليم مهارة الكتابة تدريس مهارة الكتابة تدريجيا، من المرحلة المبتدئة في وقت لاحق، وأما في ما يتعلق بالمبادئ المتعلقة بالتدردس وأن تعلم مهارة الكتابة على الأسـاس 22. على المستويات منها 1) مستوى المبتدئين 2) مستوى المتوسطة 3) مستوى المتقدمة

21 والتر ج أونج, الشفاهية والكتابية (ترجمة د.حسن البنا عزالدين كتاب عالم المعرفة 182) (كويت: عالم https://iqra.ahlamontada.com/t2288-topic.129 المعرفة, 1994)

${ }^{22}$ Iskandar Wassid and Dadang Sunendar, Strategi Pembelajaran Bahasa (Bandung: PT Remaja Rosdakarya, 2008), 292-93. 
إستراتيجية تعليم مهارة الكتابة إن مهارة الكتابة هي مستوليا على المهارة اللغوية

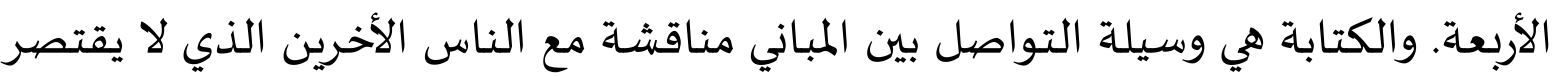
من قبل المكان والزمان. تعلم يتركز على ثلاث قضايا، وهي: القدرة على الكتابة من خلال

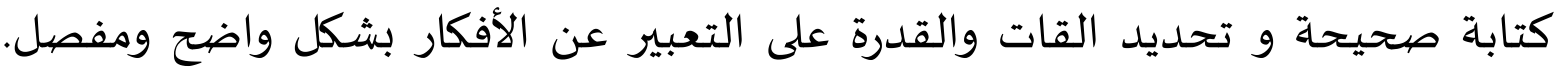

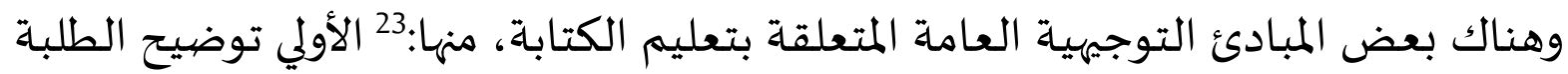

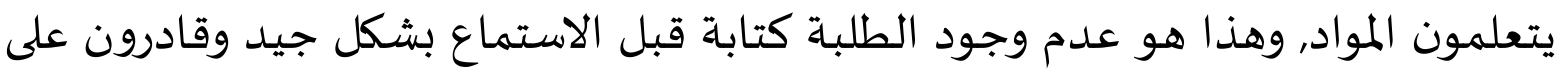

$$
\text { منهج البحثيز النطق لم يعرف القراءات والثاني إبلغ أهداف التعلم وغيرها. }
$$

أن مدخل البحث هو الكمي (Quantitative approach) الميداني. وأن البحث الكمي يهدف إلى تطوير وتوظيف النماذج الرياضية والنظريات أو الفرضيات المتعلقة بالظواهر. عملية القياس هو محور البحث الكمي لأنه يشكل رابط فعال بين الملاحظة التجريبية والتعبير

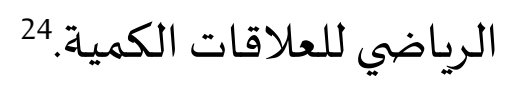

وأما المنهج هو الإرتباطية، لاكتشاف تأثير كفاءة معلمي اللغة العربية في ترقية نتيجة

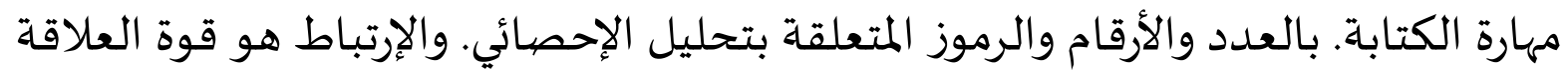

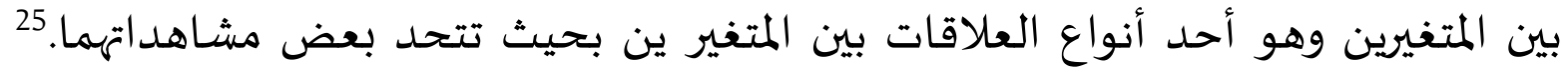

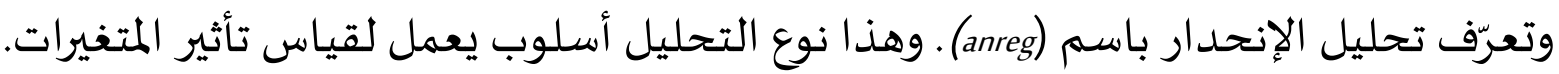
ويستخدم تحليل الإنحدار للتنبؤ بإعتماد متغير باستخدام المتغيرات المستقلة.

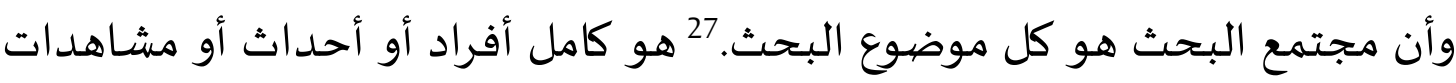

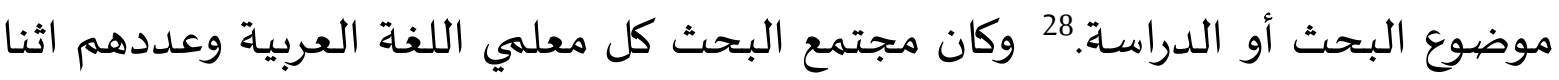
عشر معلما وجميع الطلبة في هذه المدارس وعددهم 3403 طالبا. والعينة هي عبارة عن موهن 30.

${ }^{23}$ Furqoni Aziz, Pengajaran Bahasa Komunikatif (Bandung: PT Remaja Rosda Karya, 1996), 101.

${ }^{24}$ Prof Dr Sugiyono, Metode Penelitian Kuantitatif, Kualitatif, Dan R\&D (Bandung: Alfabeta, 2016),

$$
25 \text { أحمد عبد السميع طيبه, مبادئ الاخصاء (عمان: دار البداية, 2007), } 109 .
$$

${ }^{26}$ Sugiyono, Metode Penelitian Kuantitatif, Kualitatif, Dan R\&D, 38.

${ }^{27}$ Suharsimi Arikunto, Prosedur Penelitian Suatu Pendekatan Praktik (Jakarta: Rineka Cipta, 2010), 173.

28 محمد عبيدات واصحابي،, منهجية البحث العلهي على قواعد والملدخل التطبيقات (عمان: دار وائل, 1999), 
مجموعة جزئية من الأفراد أو المشاهدات أو الظواهر التي تشكل لرتمع الدراسـة الأصلي.29 والعينة هي العينات العشوائية الطبقية النسبية (Propotional Stratified random sampling) التي يتم تقسيم مجتمع الدراسـة الأصلي إلى طبقات أو فئات معينة وفق معيار معين ويعتبر ذلك المعيار من عناصر أو متغيرات الدراسـة الهامة.30 وحددت طبقات من المستوى الصفف الأول والثاني والثالث حول المعلم الذي يتعلم فيه وحول الطلبـة في ذلك المستوى. فاختارت العينة

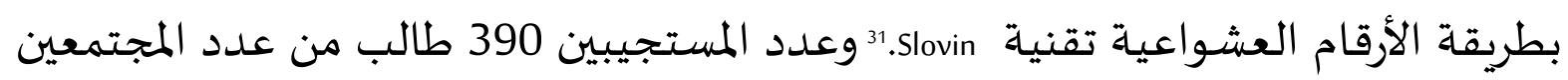
3403 طالب بمقياس ثقة البحث 95\%. وأما المتغير المستقل يعني الكفاءة التعليمياة لمعلمي اللغة العربية (x1) والكفاءة الشخصية لمعلمي اللغة العربية (x2) والكفاءة لمعلمي الاجتماعية اللغة العربية (x3) والكفاءة المهنية لمعلمي اللغة العربية (X4) والمتغير التابع (Y1) في نتيجة مهارة الكتابة لدى الطلباة. أما أدوات جمع البيانات هي الطريقه التي تستخدمها الباحثات لجمع البيانات. 32 ولمعرفة البيانات هي الإستبانة والوثائق. أما في تحليل بيانات البحث على النظرية التفاعلية بعد قيام البحث بتجميع بيانات بطريقة دراسـة الوثائق والإستبانة تأتي الخطوة التالية هي عملية تخزين البيانات واعدادها للإحصائي والبحوث إلى نتائج البحث واستخدامها صدر الأسلوب التقرير البيانات بمعرفة الإرتباط بين متغيرين. X

إن العمليات التعليمية تعتمد على أغراض التعليم الموصيوفة في خطة التدريس، وترجع هذه الأهداف التعليمية إلى منهج التعليم في أي مجال العلوم والمعارف ومنها تعليم اللغة العربية. إن أهم الأمور في مجال تعليم اللغة العربية تتوقف على الاستماع وتعليم المفردات. وأن أصعب الأمور في مجال تعليم اللغة العربية تتوقف على تعليم الكتابة،

$$
30 \text { نفس المراجع ص83 نفس المراجع ص83 }
$$

${ }^{31} \mathrm{https}: / /$ sciencing.com/slovins-formula-sampling-techniques-5475547.html.

${ }^{32}$ Mahmud, Metode Pendidikan (Bandung: Pustaka Setia, 2011), 152.

${ }^{33}$ Anas Soedijono, Pengantar Statistik Pendidikan (Jakarta: Rajawali Press, 2012), 196. 
ووجدنا مشكلات كثيرة لتحقيق أغراض التعليم مناسبا بالمنهج الدراسي. أن تأثير نجاخ التعليم يتلعق بكفاءات المعلمين بها.

أ- تأثير الكفاءة التعليمية لمعلمي اللغة العربية في نتيجة الطلبة في مهارة الكتابة

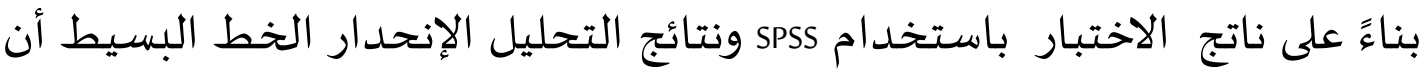

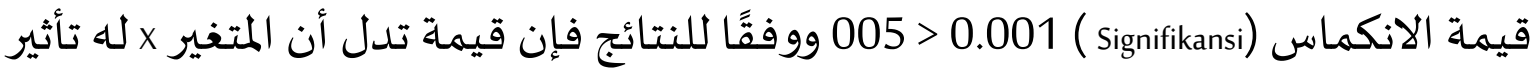

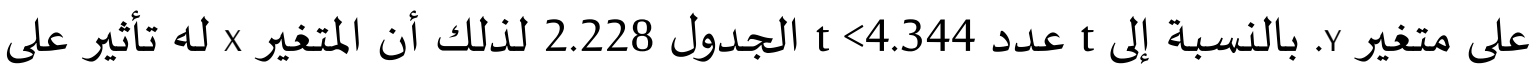

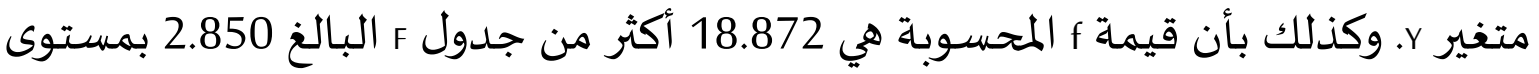
دلالة 0.001 >0.05 ، لذلك يمكن استخدام نموذج الانحدار للتنبؤ بمتغير الكفاءة التعليمية. بمعنى هناك تأثير الكفاءة التعليمية على نتائج تعلم الطلبة في مهارة الكتابة.

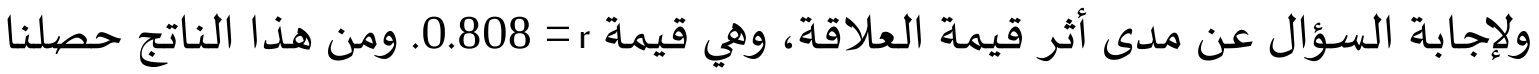

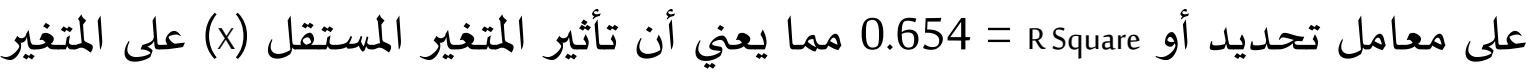

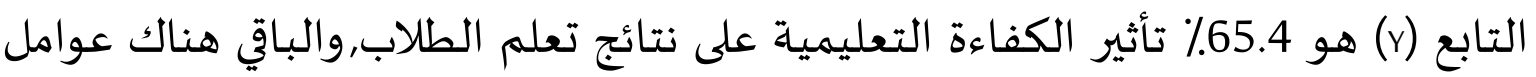
أخري خارج معادلة.

لذا فإن كفاءة معلمي اللغة العربية لها تأثير على نتائج تعلم الطلاب، مع معامل

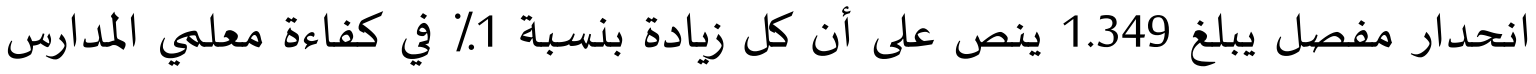

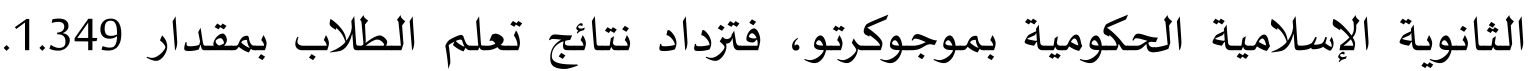
والعكس، إذا انخفضت جودة الكفاءات للمعلمين، فسوف تنخفض نتائج تعلم الطلاب. عند سوتردي أن المعلم محاول تصميم وتنفيذ أنشطة التعلم بشكل جيد، إدهوة إلا أنها قد يواجاه مشاكل التعلم في عملية التعليم. هذا نشاط ديناميكي كسبب أساسي حتى يحتاج المعلم إلى الانتباه باستمرار للتغييرات الأشياء التي تحدث للطلاب في الفصل. وللمعلم أمل

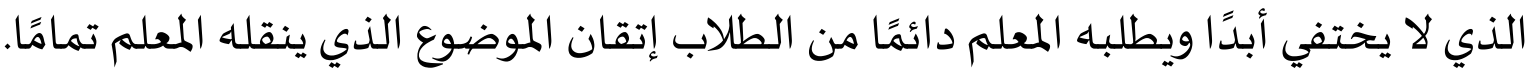

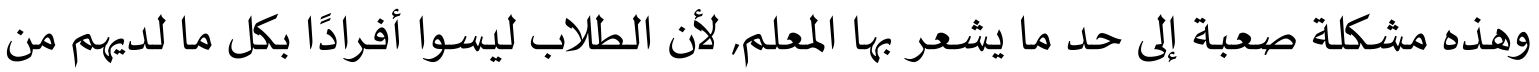

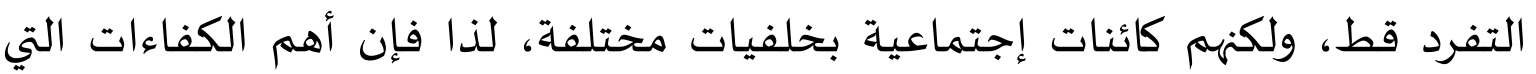

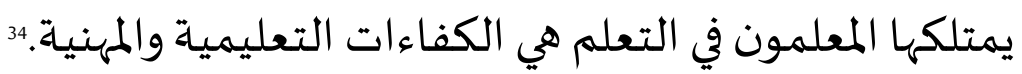

${ }^{34}$ S. Sutardi and S. Sugiharsono, "Pengaruh Kompetensi Guru, Motivasi Belajar, dan Lingkungan Keluarga terhadap Hasil Belajar Mata Pelajaran Ekonomi," Harmoni Sosial: Jurnal Pendidikan IPS 3, no. 2 (December 6, 2016): 193, https://doi.org/10.21831/hsjpi.v3i2.8400. 
استنتاجت الباحثات أن المعلم يساهم في نتائج تعلم الطلاب. فيـب على المعلمين تطوير أنفسهم باعتماد علي النفس وألا يعتمدوا على مبادرة مديري المدارس والمشرفين، General Life Skill and Specific Life (أنى يكونوا قادرين على إنتاج طلاب بمهارة حياتية عامة وخاصية Skill). يجب أن يكون المعلمون قادرين على أداء واجباتهم بشكل جيد مناسبا بالجـوانب والمؤشرات في الكفاءة التعليمية المذكورة. وهذا يدل علي أن النتيجة يتم تعزيزه بنظرية الخبراء على أن كفاءات المعلم تأثر في نتيجة الطلبـة.

\section{ب- تأثير الكفاءة الشخصية لمعلمي اللغة العربية في نتيجبة مهارة الكتابة لدى طلبة} بناءً على ناتج الاختبار باستخدام SPSS ونتائج التحليل الإنحدار الخط البسيط أن قيمة الانكماس (Signifikansi) (2x) 0.021 005 يمكن استنتاج أن المتغير له تأثير على متغير Y. بالنسبة إلى t عدد 2.745 الجدول 2.228 لذلك الإستنتاج أن المتغير x لله تأثير على متغير Y. وكذلك بأن قيمة f المحسوبة هي 7.534 أكثر من جدول F البالغ 2.850 بمستوى دلالة 0.021 >050 ، لذلك يمكن استخدام نموذج الإنحدار للتنبؤ بمتغير الكفاءة الشخصية. بمعنى هناك تأثير الكفاءة الشخصيية على نتائج تعلم الطلبة في مهارة الكتابة ولإجابة السؤال عن مدى أثر قيمة العلاقة، وهي قيمة r = 0.655. ومن هذا الناتج حصيلنا على معامل تحديد أو R Square = 0.430 مما يعني أن تأثير المتغير المستقل (x) على المتغير التابع (r) هو 13 تأثير الكفاءة الشخصيية على نتائج تعلم الطلاب,والباقي هناك عوامل أخري خارج معادلة. لذا فإن كفاءة معلمي اللغة العربية الشخصية لها تأثير على نتائج تعلم الطلاب، مع معامل إنحدار مفصل يبلغ 1.347 ينص على أن كل زيادة بنسبة 1\% في كفاءة معلمي المدارس الثانويـة الإسلامية الحكومية بموجوكرتو، فتزداد نتائج تعلم الطلاب بمقدار 1.347.والعكس، إذا انخفضت جودة الكفاءات للمعلمين، فسوف تنخفض نتائج تعلم الطلاب.

هناك نتائج البحث من دراسـة سـواردي (2018) عنوان البحث هي " تأثير شخصية معلم دين الإسـلام على نتائج تعلم الطلاب في المدرسـة". ووجدت نتائج الدراسـة أن نتيجة تعلم الطلاب تتأثر بعدة عوامل مهمة وتقع على عاتق المعلم مسؤولية تحقيق ذلك مثل التحفيز ، ولا ينشأ الدافع إلا إذا كانت هناك رغبة في النجاح في التعلم، لذلك تؤثر 
شخصية المعلم بشكل كبير على الطلاب في عملية التعلم حتى يتمكنوا من تحسين نتائج

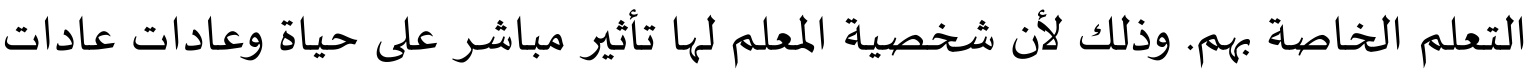

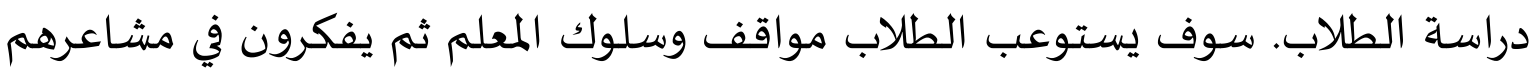
من خلال تقليد السلوك واقتباس تصريحات المعلم وبياناته. تظهر التجربة أن الأشياء المختلفة المتعلقة بالتحفيز والانضباط والسلوك الاجتماعي والإنجاز والرغبة في التعلم تأتي

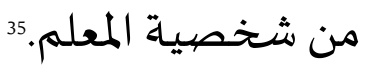
سيقوم المعلمون الودودون والمهتمون بتهيئة موقف مواتٍ بإعطاء هالة إيجابية للتطور نفس الطلاب. فسيشعر الطلاب بالأمان والراحة والسعادة للتعلم في الفصل. فسيكون الطلاب متحمسين للتعلم ومستعدون للإمتثال وللقواعد الصيادرة عن المعلم. ومن ناحية أخرى، سيخلق المعلم الصاخب والغاضب مناخًا متوترًا في الفصل الدراسي. فيمكن فئن

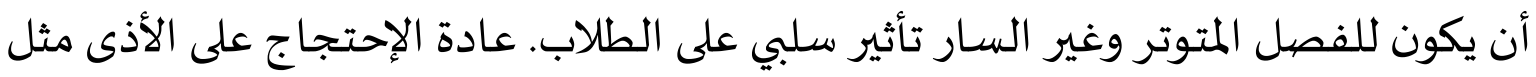

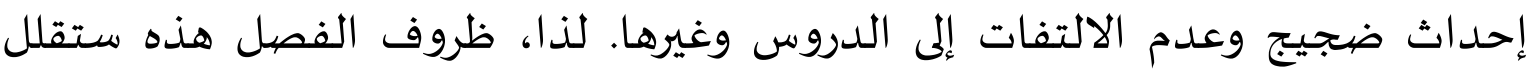

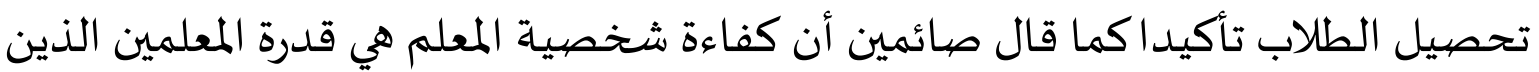
يعكس شخصية ثابتة ومستقرة وناضجة وحكيمة وموثوقة، ويصبح نموذجًا يحتذى بهاه

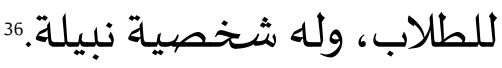
أن هذه نتائج الدراسة لها تأثير كبير في نتيجة الطلبة فتكون تعزيزة لنتائج البحث

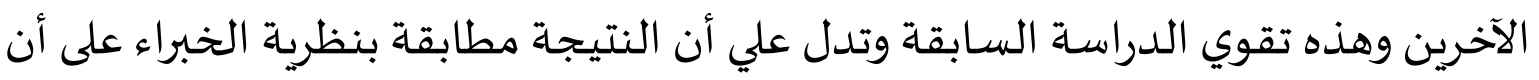

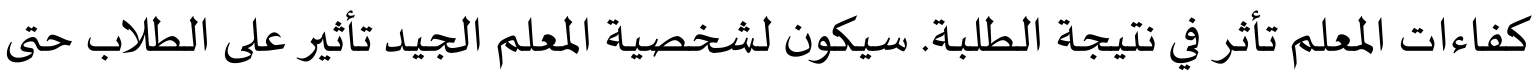

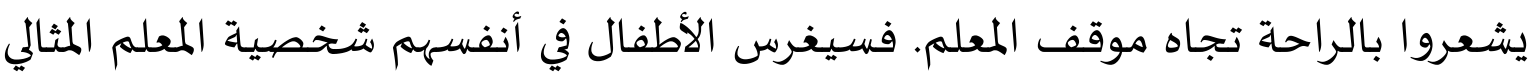
ويصبحون صنمًا لبقياة حياته. هذه الراحة ستجلب الحالة النفسية للطلاب وعقلهم الباطن إلى تفضيل الدروس التي يقدمها المعله. حتى يفهم الأطفال المادة دون الشعور

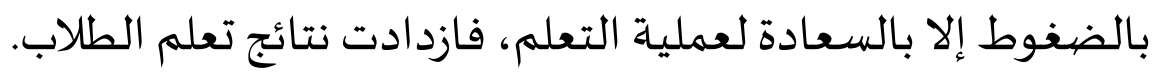
ج-تأثير الكفاءة الاجتماعية لمعلمي اللغة العربية علي نتائج تعلم الطلبة في مهارة الكتابة

${ }^{35}$ Suardi M, "Pengaruh kepribadian guru pai terhadap hasil belajar siswa di sekolah," IQRO: Journal of Islamic Education 1, no. 2 (2018): 121, https://doi.org/10.24256/iqro.v1i2.494.

${ }^{36}$ Arison Shoimin, Guru Berkarakter Untuk Implementasi Pendidikan Karakter (Yogjakarta: Gava Media, 2014), 49. 


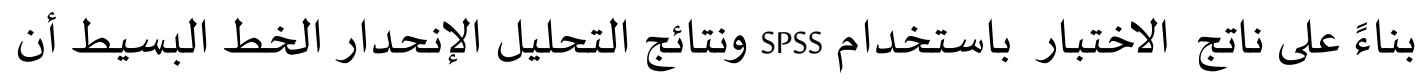

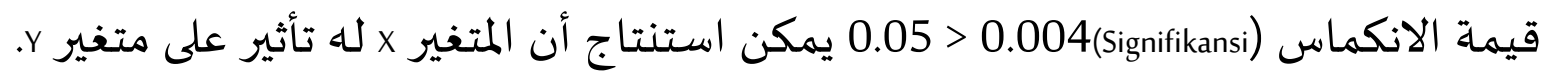

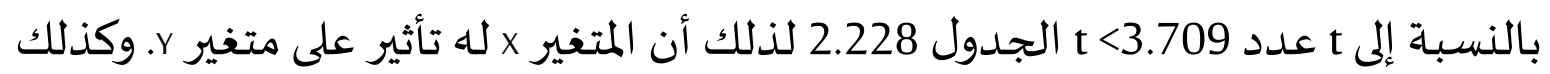
بأن f المحسوبة هي 13.755 أكثر من جدول F البالغ 2.850 بمستوى دلالة 0.004 >0.05 ،

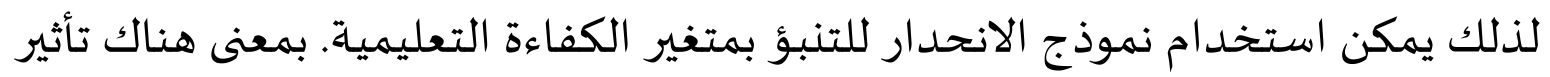

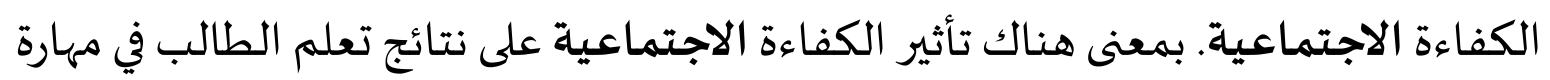

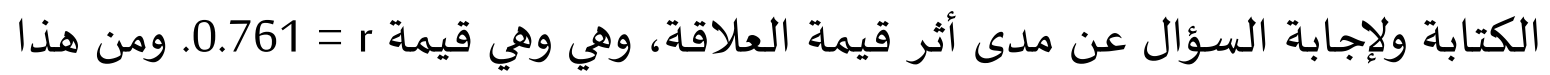

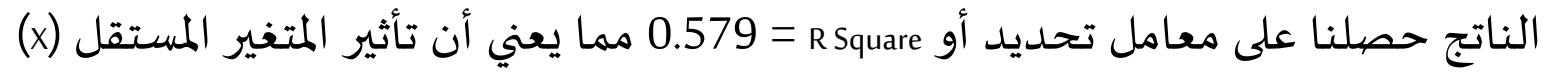
على المتغير التابع (Y) هو 57.9٪ تأثير الكفاءة الاجتماعية على نتائج تعلم الطلاب، والباقي تهابي هناك عوامل أخري خارج معادلة.

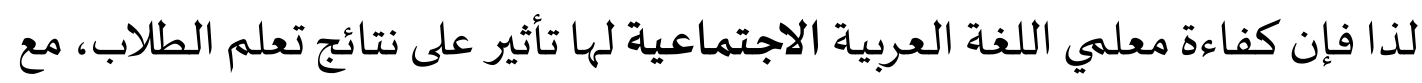

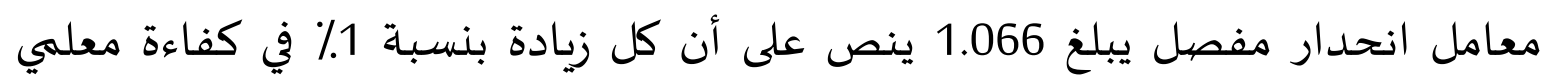

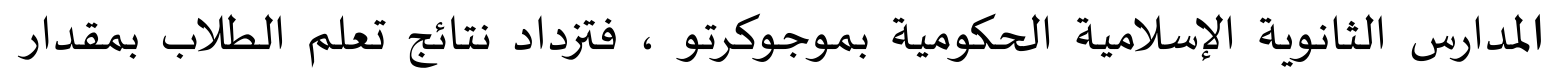

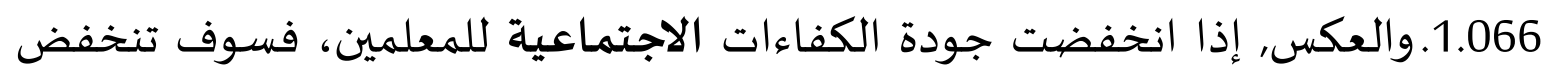
نتائج تعلم الطلاب. وفقًا لرأي آدم (في مرتاني وأدينتي)، فإن الكفاءة الاجتماعية لها علاقة وثيقة بالتكيف

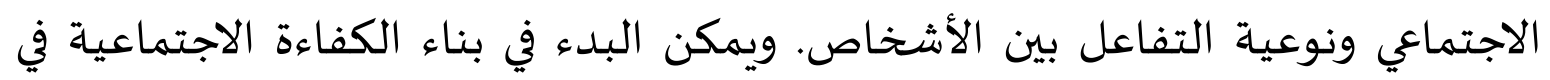

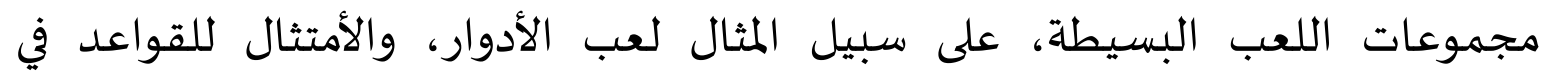

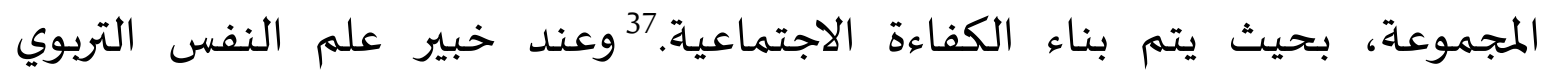
جادنر(Gardner) أن الكفاءة الاجتماعية بالذكاء الاجتماعي أوالذكاء الاجتماعي. والذكاء

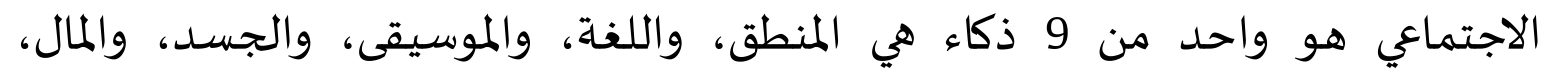
والشخصيية، والطبيعة الخادعة. أن تدريس الطلاب في الفصل هو مظهر من مظاهر التفاعل في عملية الإتصال. بينما

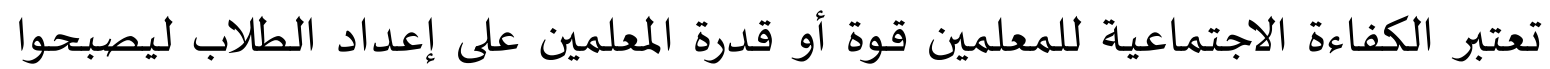

${ }^{37}$ Wisjnu Martani and M. G. Adiyanti, “Kompetensi Sosial Dan Kepercayaan Diri Remaja,” Jurnal PsikologiI, 1991, 17-20.

${ }^{38}$ Howard Gardner, “Multiple Intelligences (Kecerdasan Majemuk Teori Dalam Praktek)., 1983. 
أفرادا صالحين في المجتمع والقدرة على تثقيف وتوجيا المجتمع في المستقبل. لذلك، يمكن للمدرسين أن يخلقوا الظروف التعليمية المريحة. 39

شرحت نانا سوجانا في كتابها أن نتائج تعلم الطلاب هي تغييرات في السلوك ونتيجة

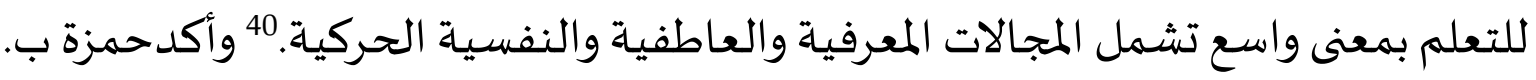

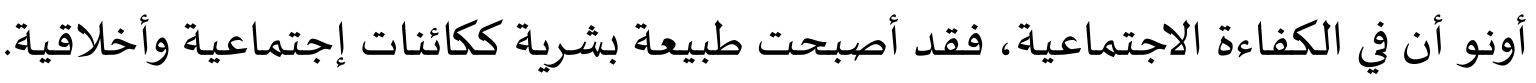

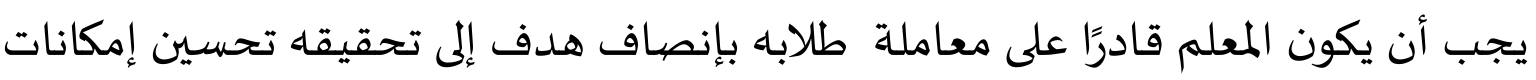

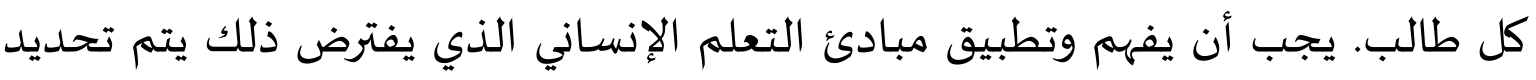

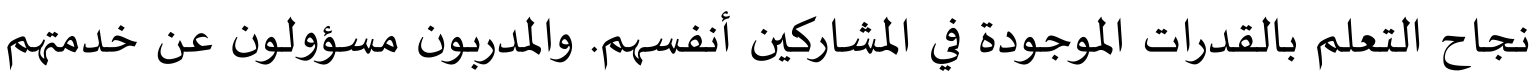

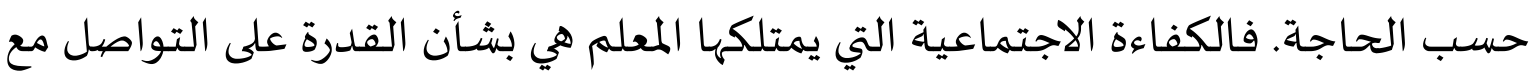
الطلاب والبيئة (مثل الآباء والجيران والأصيدقاء).

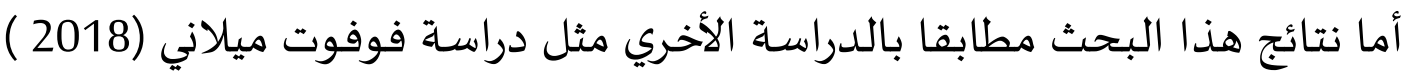

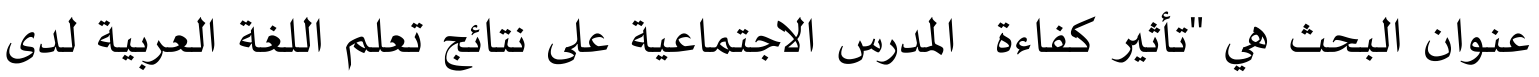

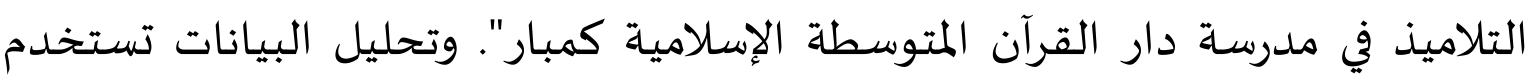
الباحثات طريقة تحليل الإنحدار الخطي البسيط بمساعدة برنامج الإحصائي للعلوم

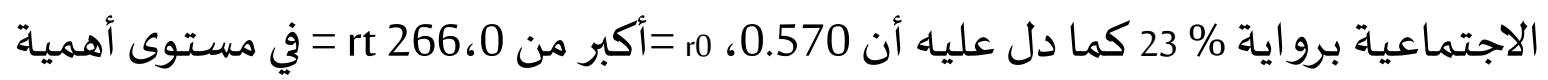

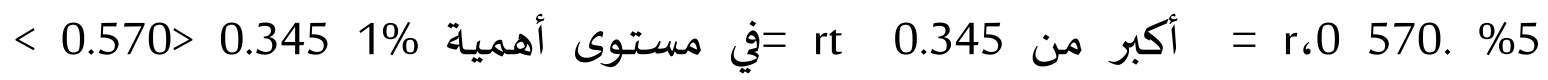

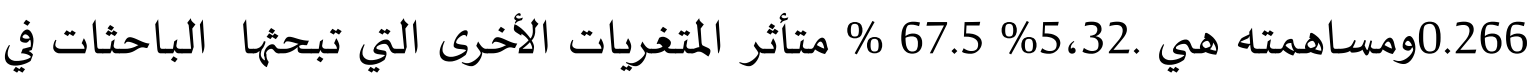
هذا البحث. ودراسـة البحث الأخر هي دراسـة للؤلؤة اللطفية وإيني وينارتي (2017) عنوان البحث هي "تأثير الكفاءة الاجتماعية للمعلم على نتائج تعلم الطلاب في المدرسـة الثانوية الإسلامية

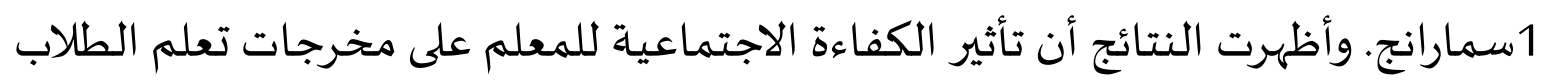

${ }^{39}$ Lia Lu'lu'ul Lutfiyah and Eni Winaryati, "Pengaruh Kompetensi Sosial Guru terhadap Hasil Belajar Siswa (di SMA Muhammadiyah 1 Semarang)," PROSIDING SEMINAR NASIONAL \& INTERNASIONAL 0, no. (2017): 208, http://103.97.100.145/index.php/psn12012010/article/view/3061.

${ }^{40}$ Sudjana, Penilaian Hasil Proses Belajar Mengajar, 5.

${ }^{41}$ PUPUT MELANI, "Pengaruh Kompetensi Sosial Guru Terhadap Hasil Belajar Bahasa Arab Siswa di Madrasah Tsanawiyah Darul Qur'an Kampar" (skripsi, Universitas Islam Negeri Sultan Syarif Kasim Riau, 2018), wawu, https://doi.org/10/10.\%20BAB\%20V_2018708PBA.pdf. 
قد تم إثباته من قبل العديد من الطلاب المهتمين، ويمكنهم أداء التمارين التي قدمها المعلمون، وكان متوسط الدرجة جيدًا.

سيؤثر التفاعل الاجتماعي للمعلم الجيد والظروف التعليمية المريحة على نتائج تعلم الطلاب حتى أن الموقف الاجتماعي للمعلم سيتذكره الطلاب دائمًا إلى الأبد، على سبيل المريل

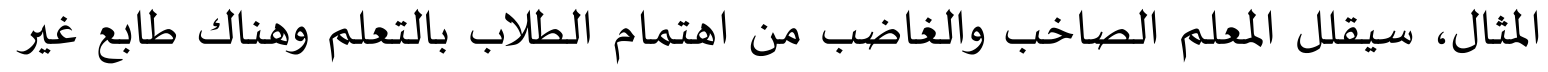
مكتوب أن المعلم هو مدرس صعب. والعكس، فإن الموقف الاجتماعي للمعلم اللطيف وإهتماماه في الإتصال والتمويل سيكون لـه تأثير كبير على نتائج التعلم ومواقف الطلاب التي تجعل المعلم معبودًا في كل العصور.سيقلل الموقف الاجتماعي للمعلم في التواصل المفتوحة من توتر الطلاب في التعلم. ومن الناحية النفسية، فإن مثل هذه الظروف تجعل الأطفال

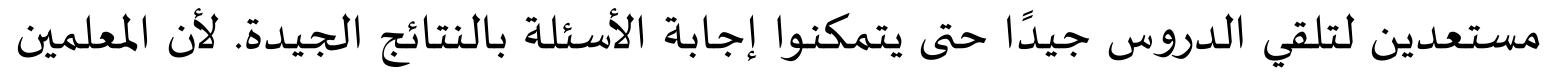

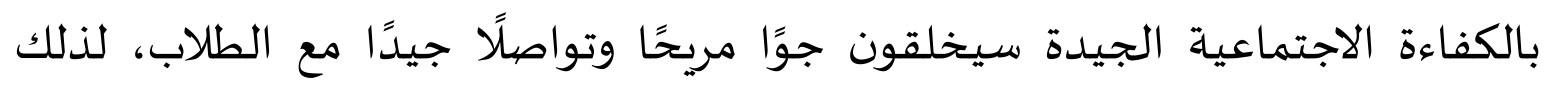

$$
\text { سيحاول الطلاب الحصول على نتائج جيدة. }
$$

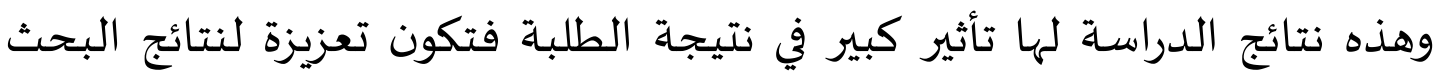

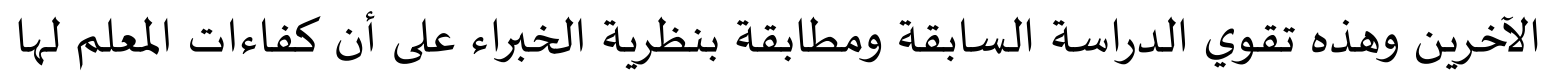
تأثير في نتيجة الطلبة.

د- تأثير الكفاءة المهنية لمعلمي اللغة العربية علي نتائج تعلم الطلبة في مهارة الكتابة

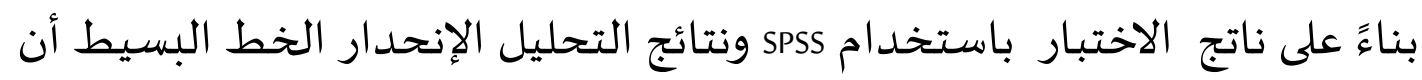

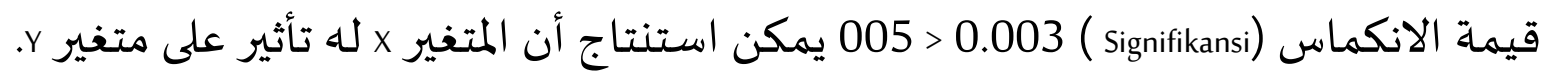

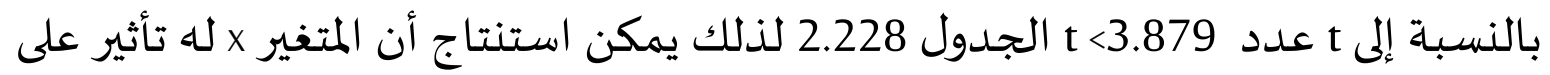

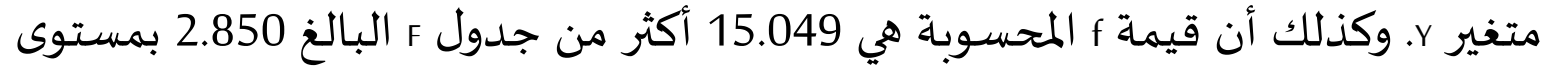
دلالة 0.003 >0.05 ، لذلك يمكن استخدام نموذج الانحدار للتنبؤ بمتغير الكفاءة المهنية.

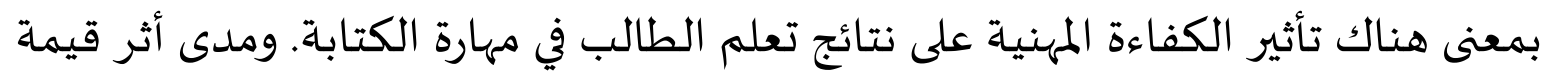

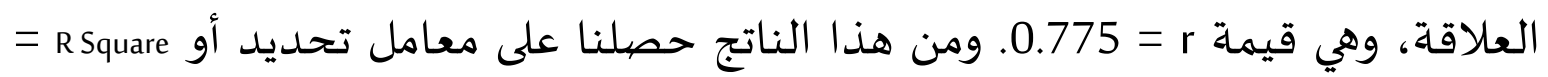

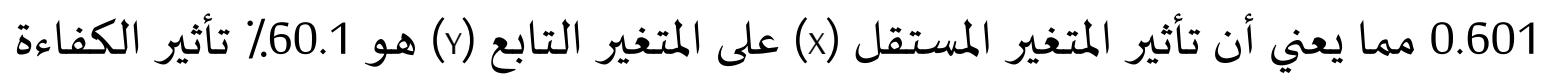
المهنية على نتائج تعلم الطلاب,والباقي هناك عوامل أخري خارئ المعارج معادلة.

\footnotetext{
${ }^{42}$ Lutfiyah and Winaryati, "Pengaruh Kompetensi Sosial Guru Terhadap Hasil Belajar Siswa (di SMA Muhammadiyah 1 Semarang)," 207.
} 
لذا فإن كفاءة معلمي اللغة العربية المهنية لها تأثير على نتائج تعلم الطلاب، مع معامل

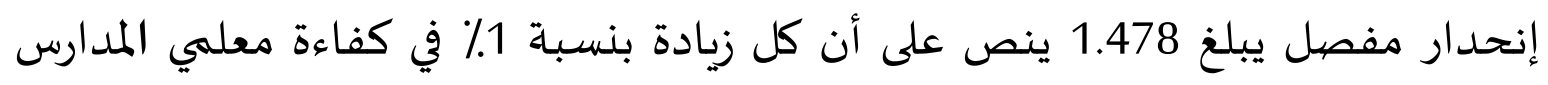
الثانوية الإسلامية الحكومية بموجوكرتو، فتزداد نتائج تعلم الطلاب بمقدار 1478. والعكس، إذا انخفضت جودة الكفاءات للمعلمين، فسوف تنخفض نتائج تعلم الطلاب. أكدت دراسة جعفر الصديق ونور شام (2020) بعنوان البحث هو تأثير الكفاءة إنداء

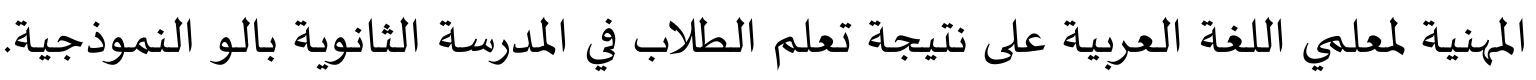

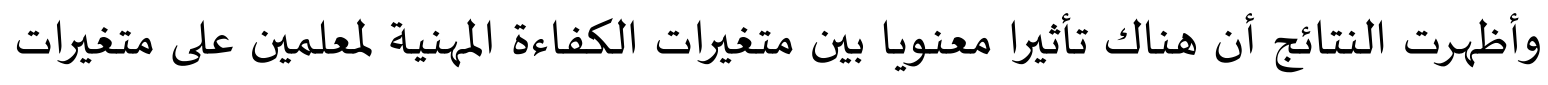

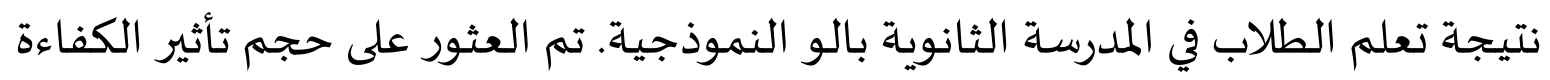

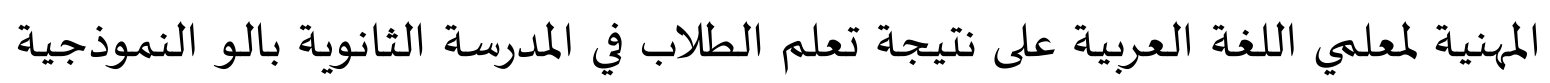
بنسبة 40.1٪ بينما تأثرت نسبة 59.9٪ المتبقية بعوامل أخرى غير مدرجة فئس في هذه الدراسـة.

أن هذه نتائج الدراسـة لها تأثير كبير في نتيجة الطلبة فتكون تعزيزة لنتائج البحث

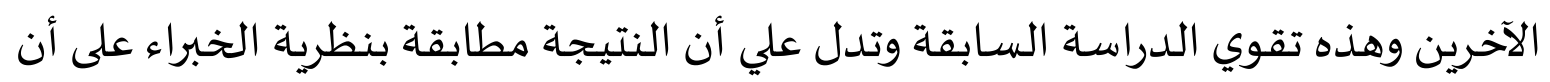

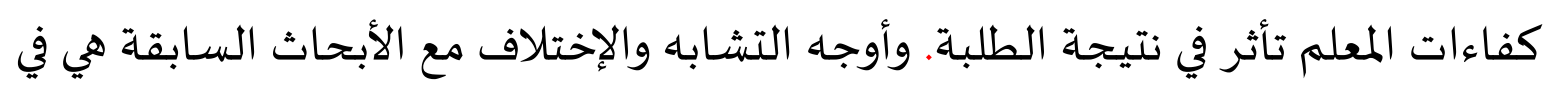
قياس تأثيرها و مجال جوانها. من هذه النتيجة نعرف أن جوهر التعلم هو التدريس واتس

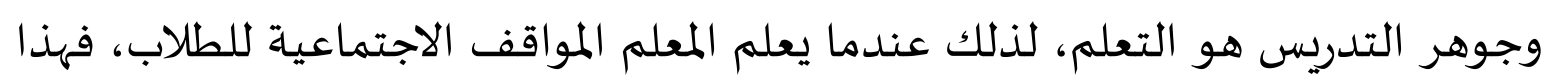

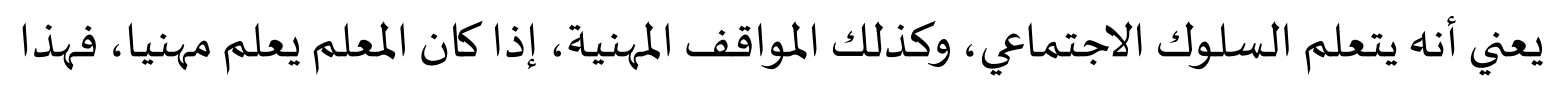
يعني أنها يعطي أمثلة بحيث يمكن للطلاب أن يكونوا محترفين في جميع المجالات.

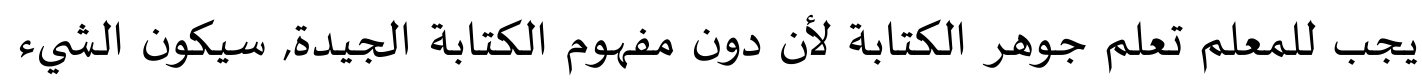

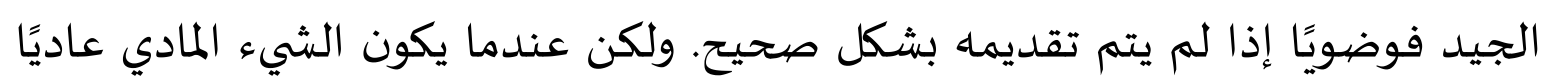

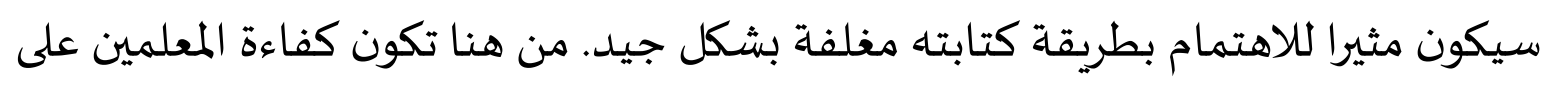

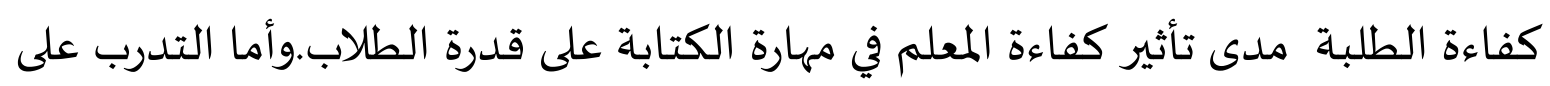

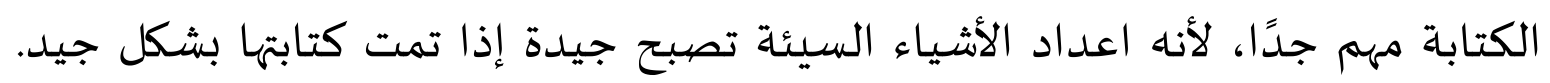

${ }^{43}$ Jafar Sidik and Nursyam, "Pengaruh Profesionalisme Guru terhadap Hasil Belajar Peserta Didik Pada Mata Pelajaran Bahasa Arab di Madrasah Tsanawiyah Negeri Model Palu," Albariq: Jurnal Pendidikan Bahasa Arab 1, no. 2 (December 23, 2020): 45, https://doi.org/10.24239/albariq.v1i2.10. 
علاوة على ذلك، إذا كان الموضوع جيدًا في يد كاتب جيد، فستكون متعجبة للقراء. علينا أن نعرف أن يستغرق تكوين هذه المهارة وقتًا طويلاً وقوة التعلم ثم التعلم بالاستمرار.

خاتمة

أ. حصلت الكفاءة التعليمية على معلمي اللغة العربية في المدارس الثانوية الإسلامية الحكومية بموجوكرتو في وضع أو فئة جيدة فيؤثر حجم الكفاءة التربوية للمعلم المئم

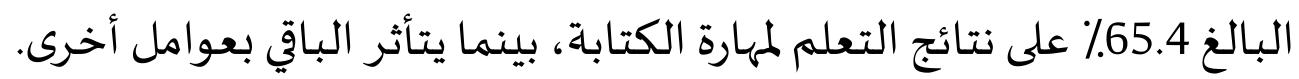
ب. الكفاءة الشخصية لمعلمي اللغة العبية في المدارس الثانوية الإسلامية الحكومية

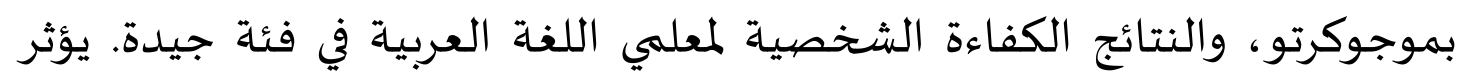
حجم كفاءة شخصية المعلم بنسبة 43٪ على مخرجات التعلم لمهارة الكتابة، بينما

$$
\text { يتأثر الباقي بعوامل أخرى. }
$$

ت. الكفاءة الاجتماعية لمعلمي اللغة العربية في المدارس الثانوية الإسلامية الحكومية

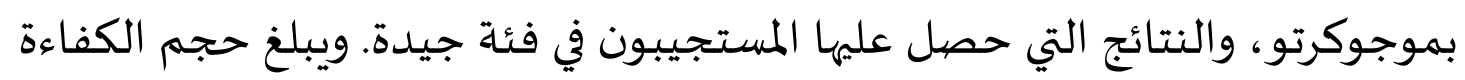
الاجتماعية للمعلم 57.9٪، مما يؤثر على مخرجات التعلم لمهارة الكتابة، بينما يتأثر

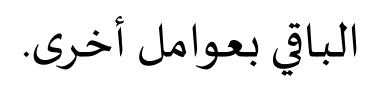

الكفاءة المهنية لمعلمي اللغة العربية في المدارس الثانوية الإسلامية الحكومية

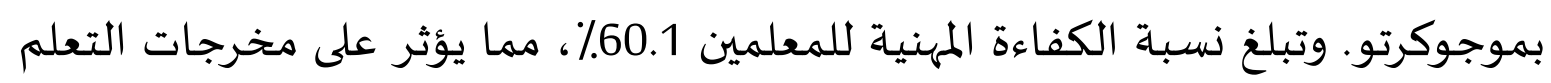

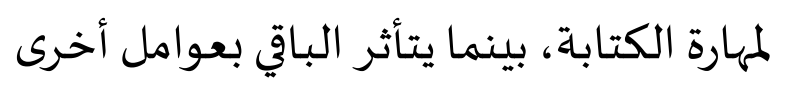

Al Maujud, Fataha. Madhkal Ila Tadriys Al Ughah Al 'Arabiyyah. Mataaram: Muassasah Al Matr, 2009.

Al Wasilah, A Chaedar, and Senny Susana. Pokoknya Menulis. Bandung: Kiblat Buku Utama, 2008.

Arikunto, Suharsimi. Prosedur Penelitian Suatu Pendekatan Praktik. Jakarta: Rineka Cipta, 2010.

Arikunto, Suharsimi, and Cepi Safrudin Abdul Jabar. Evaluasi ProgramPpendidikan. Jakarta: Bumi Aksara, 9AD.

Aziz, Furqoni. Pengajaran Bahasa Komunikatif. Bandung: PT Remaja Rosda Karya, 1996. 
Departemen Pendidikan Nasional. "Kegiatan Belajar Mengajar Yang Efektif.” Jakarta, 2003.

DEPDIKNAS. "Lampiran Permendiknas No 16 Tahun 2007, Standar Kualifikasi Akademik Dan Kompetensi Guru Mata Pelajaran Di SD/MI, SMP/MTs, SMA/MA, AMK/MAK," 2017.

. "UU RI Nomor 14 Tahun 2005 Tentang Guru Dan Dosen.” Jakarta: DEPDIKNAS, 2005.

Gardner, Howard. "Multiple Intelligences (Kecerdasan Majemuk Teori Dalam Praktek), 1983.

Ihsan, Mohammed. Kafaat Mu'allimiy Al Lughah Al 'Arabiyyah Fi Al Madaris Al Mutawassithah Al Islamiyyah Bi Mantiqah Bima Nusa Tinjaara Al Gharbiyyah. Malank: Al Jami'ah Al Islamiyyah Al Hukumiyyah Malanj, 2018.

Khinji, Al Duktur Zakariya. " Al Mua'allim Adwaruhu Wa Ahammiyatuhu." Akhbar Al Khaliij Al Jaridah Al Yaumiyyah Al Uula.2021, Qadaaya Wa Araa'.

Kuraedah, Sitti. "Aplikasi Maharah Kitabah Dalam Pembelajaran Bahasa Arab.” Al-TA'DIB: Jurnal Kajian Ilmu Kependidikan 8, no. 2 (2015): 82-98.

Lutfiyah, Lia Lu'lu'ul, and Eni Winaryati. "Pengaruh Kompetensi Sosial Guru Terhadap Hasil Belajar Siswa (di SMA Muhammadiyah 1 Semarang)." Prosiding Seminar Nasional \& Internasional $\quad 0, \quad$ no. http://103.97.100.145/index.php/psn12012010/article/view/3061.

M, Suardi. "Pengaruh Kepribadian Guru Pai Terhadap Hasil Belajar Siswa Di Sekolah." Iqro: Journal of Islamic Education 1, no. 2 (2018): 121-28. https://doi.org/10.24256/iqro.v1i2.494.

Mahmud. Metode Pendidikan. Bandung: Pustaka Setia, 2011.

Martani, Wisjnu, and M. G. Adiyanti. "Kompetensi Sosial Dan Kepercayaan Diri Remaja." Jurnal PsikologiI, 1991, 17-20.

Maghfur, Ahmad 'Ali. Ta'dir Afaah Mu'allimiy Al 'Arabiyyah Al Ta'limiyyah Wa Almihniyyah Fi Tarqiyyah Injaz Al Thalabah. Malanj: Al Jami'ah Al Islamiyyah Al Huumiyyah Malanj, 2020.

Melani, Puput. "Pengaruh Kompetensi Sosial Guru Terhadap Hasil Belajar Bahasa Arab Siswa Di Madrasah Tsanawiyah Darul Qur'an Kampar.” Skripsi, Universitas Islam $\begin{array}{lllll}\text { Negeri Sultan } & \text { Syarif } & \text { Kasim }\end{array}$ https://doi.org/10/10.\%20BAB\%20V_2018708PBA.pdf.

Mulyasa, E. Menjadi Guru Profesional (Menciptakan Pembelajaran Kreatif Dan Menyenangkan). Bandung: PT Remaja Rosda Karya, 2010.

—. Standar Kompetensi Dan Sertifikasi Guru. Bandung: PT Remaja Rosdakarya, 2008.

Nurdin, Muhammad. Kiat Menjadi Guru Profesional. Yogjakarta: Ar-Ruzz Media, 2008. 
Nurdin, Syafrudin, and Basyirudin Usman. Guru Profesional Dan Implementasi Kurikulum. Jakarta: Ciputat Pers, 2002.

Pusat Bahasa, Tim Penyusun Kamus. Kamus Besar Bahasa Indonesia. Jakarta: Balai Pustaka, 2008.

Shoimin, Arison. Guru Berkarakter Untuk Implementasi Pendidikan Karakter. Yogjakarta: Gava Media, 2014.

Sidik, Jafar, and Nursyam. "Pengaruh Profesionalisme Guru Terhadap Hasil Belajar Peserta Didik Pada Mata Pelajaran Bahasa Arab Di Madrasah Tsanawiyah Negeri Model Palu." Albariq: Jurnal Pendidikan Bahasa Arab 1, no. 2 (December 23, 2020): 45-61. https://doi.org/10.24239/albariq.v1i2.10.

Soedijono, Anas. Pengantar Statistik Pendidikan. Jakarta: Rajawali Press, 2012.

Sugiyono, Prof Dr. Metode Penelitian Kuantitatif, Kualitatif, Dan R\&D. Bandung: Alfabeta, 2016.

. Metode Penelitian Pendidikan. Bandung: Alfabeta, 2010.

Suriya, Wahyu Hutamaa. Ta'siir Al Kafaah Al Mihniyyah Li Mudarris Al Lughah Al 'Arabiyyah 'Ala Natiijah Ta'llum Tullab Nahdhah Al 'Ulama Al Uwla Al Mutawassithah Biburujati Fi Al Sanah Al Diraasah 201902020, Malanj: Al Jami'ah Al Islamiyyah Al Hukumiyyah Malanj, 2020.

Sutardi, S., and S. Sugiharsono. "Pengaruh Kompetensi Guru, Motivasi Belajar, Dan Lingkungan Keluarga Terhadap Hasil Belajar Mata Pelajaran Ekonomi." Harmoni Sosial: Jurnal Pendidikan IPS 3, no. 2 (December 6, 2016): 188-98. https://doi.org/10.21831/hsjpi.v3i2.8400.

Syibli, Rafif. " Al Kitabah Bi Al Qalam Tusa'idu Al Tullab 'Ala Hifz Al Malimamaat" Al 'Arabiyyah, April 10, 2014. https://www.alarabiya.net/last-page/2014/04/10.

Tha'imah, Rusydi Ahmad. Ta'liim Al 'Arabiyyah Lighair Al Natiqiin Bihaa Manaahijuhu Wa Asaliybuhu. Al Rabaat, Magrib: Mansyuurat Al Munazzamah Al Islamiyyah Li Al Tarbiyyah Wa Al'ulum Wa Al Tsaqafah, 1998.

Unaj Wa Al Tarj. Al Syafahiah Wa Alk Itabiyah (Tarjamah Dr. Hasan Al Bana 'Izzuddin Kitab 'Alam Al Ma'rifah 182) Uwait: 'Alam Al Marifah, 1994. . Https://Iqra.Ahlamontada.Com/T2288-Topic

Wahidmurni, Prof. Keterampilan Dasar Mengajar. Yogjakarta: Ar-Ruzz Media, 2010. 